\title{
Percepção da Educação Física na formação humana, integral e omnilateral de discentes da Educação Profissional Técnica Federal na Amazônia, Brasil
}

\author{
Perception of physical education in the human, unabridged and omnilateral shaping of students of \\ federal technical professional education in the amazon region, Brazil \\ Percepción de la educación física en la formación humana, integral y omnilateral de estudiantes de \\ educación profesional técnica federal en la región amazónica, Brasil
}

Recebido: 18/07/2021 | Revisado: 25/07/2021 | Aceito: 28/07/2021 | Publicado: 04/08/2021

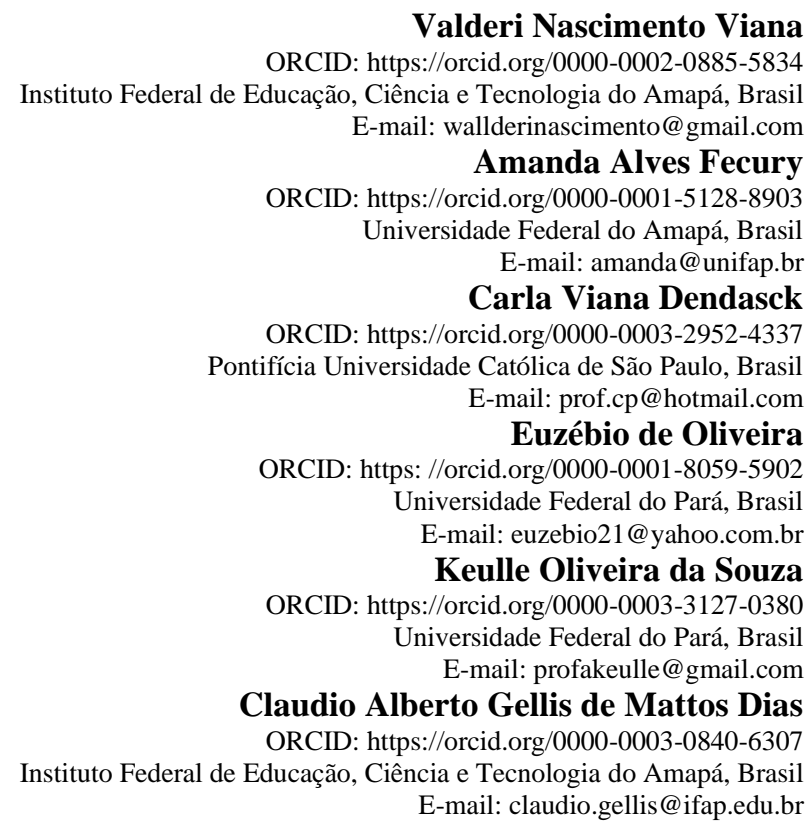

\section{Resumo}

Na educação ocidental, a formação humana está relacionada a humanização do homem, pois é um ser que não nasce pronto, mais que precisa ser educado/humanizado. A formação omnilateral propõe um ensino para um homem-genérico, para isso, ocorre a união entre trabalho, ciência e cultura. No decorrer da história tanto a educação profissional e tecnológica (EPT) quanto a educação física passaram por mudanças, por motivos sociais e políticos. O objetivo geral deste estudo foi verificar a percepção do discente da educação profissional e técnica federal acerca do papel da educação física em sua formação integral e humanizada. Os resultados apresentados pela pesquisa evidenciaram que os professores trabalham uma educação física que vai além do esporte pelo esporte, proporcionam aos alunos uma vivência de uma pratica mais crítica, que visa realmente contribuir para a formação do cidadão. As diversas maneiras de trabalhar os conteúdos junto com a experiência pratica de certa forma vão refletir em como os alunos percebem uma determinada componente curricular. E os educandos percebem que não há uma formação integral sem a presença da educação física, pois é uma área que lida com o ser humano como um todo, desde sua estrutura anatômica a desenvolvimento de nexos sociais. Reconhece-se os limites presentes no estudo por causa do período pandêmico, não acontecendo um contato mais próximo com os educandos. Espera-se que essa pesquisa possa contribuir para novos estudos na área da educação física, que estimule um olhar e a curiosidade nessa área do conhecimento que é tão rica e ampla. Esse trabalho torna-se mais uma peça no quebra cabeça do conhecimento científico sobre a relação da educação física e a formação omnilateral. Palavras-chave: EPT; Educação física; IFAP; Omnilateral; Integral.

\begin{abstract}
In Western education, human formation is related to the humanization of man, as he is a being who is not born ready, but needs to be educated/humanized. Omnilateral training proposes a teaching for a generic man, for this, there is a union between work, science and culture. Throughout history, both professional and technological education (PTE) and physical education have undergone changes for social and political reasons. The general objective of this study was to
\end{abstract}


verify the perception of federal professional and technical education students about the role of physical education in their comprehensive and humanized training. The results presented by the research showed that teachers work with a physical education that goes beyond sport for sport, providing students with an experience of a more critical practice, which aims to really contribute to the formation of citizens. The various ways of working the contents together with practical experience will somehow reflect on how students perceive a particular curricular component. And the students realize that there is no comprehensive training without the presence of physical education, as it is an area that deals with the human being as a whole, from its anatomical structure to the development of social connections. The limits present in the study are recognized due to the pandemic period, with no closer contact with the students. It is hoped that this research can contribute to new studies in the field of physical education, which stimulates a look and curiosity in this area of knowledge, which is so rich and wide. This work becomes another piece in the puzzle of scientific knowledge about the relationship between physical education and omnilateral training.

Keywords: EPT; Physical education; IFAP; Omnilateral; Full.

\section{Resumen}

En la educación occidental, la formación humana está relacionada con la humanización del hombre, ya que es un ser que no nace preparado, pero necesita ser educado / humanizado. La formación omnilateral propone una enseñanza para un hombre genérico, para ello existe una unión entre trabajo, ciencia y cultura. A lo largo de la historia, tanto la educación profesional y tecnológica (EPT) como la educación física han sufrido cambios por motivos sociales y políticos. El objetivo general de este estudio fue verificar la percepción de los estudiantes de educación técnica y profesional federal sobre el papel de la educación física en su formación integral y humanizada. Los resultados presentados por la investigación mostraron que los docentes trabajan con una educación física que va más allá del deporte por deporte, brindando a los estudiantes una experiencia de una práctica más crítica, que tiene como objetivo contribuir realmente a la formación de los ciudadanos. Las diversas formas de trabajar los contenidos junto con la experiencia práctica reflejarán de alguna manera cómo los estudiantes perciben un componente curricular en particular. Y los alumnos se dan cuenta de que no hay formación integral sin la presencia de la educación física, ya que es un área que se ocupa del ser humano en su conjunto, desde su estructura anatómica hasta el desarrollo de las conexiones sociales. Los límites presentes en el estudio se reconocen debido al período pandémico, sin un contacto más cercano con los estudiantes. Se espera que esta investigación pueda contribuir a nuevos estudios en el campo de la educación física, que estimulen la mirada y la curiosidad en esta área de conocimiento tan rica y amplia. Este trabajo se convierte en una pieza más en el rompecabezas del conocimiento científico sobre la relación entre educación física y entrenamiento omnilateral.

Palabras clave: EPT; Educación Física; IFAP Omnilateral; Completo.

\section{Introdução}

\subsection{O Papel da Educação Física na EPT (De Nilo Peçanha ao Instituto Federal)}

A Educação ísica chegou ao Brasil com a família real portuguesa (chamada ginástica), e mesmo a serviço de interesses da classe dominante sofreu resistência, pois os filhos dessa classe deveriam realizar trabalho intelectual e não físico (Cavalheiro \& Gomes, 2014).

A educação profissional tem seu início no Brasil Imperial. Nesse período ela era desvalorizada (Marin et al., 2019; Viana, Oliveira, et al., 2020). Em 1910 dezenove Escolas de Aprendizes Artífices foram inauguradas nas capitais dos estados brasileiros, durante a passagem de Nilo Peçanha pela presidência da república (Ramos, 2014). Por causa do crescimento populacional nas cidades, teria que haver um meio para a classe proletária sobreviver. Além de oferecer a habilidade técnica e intelectual, criaria hábitos de trabalho, evitando o tempo ócio, os vícios e o crime (Marin et al., 2019).

No decorrer da história tanto a educação profissional e tecnológica (EPT) quanto a educação física passaram por mudanças, por motivos sociais e políticos. Na década de 30, era uma educação para o trabalho industrial, atrelada ao patriotismo e educação do corpo saudável. Durante a ditadura militar, na EPT, a educação física teria um papel de disciplinar com as aulas voltadas exclusivamente para práticas. Na década de 1990, escolas técnicas e agrotécnicas são transformadas em CEFETs Centros Federais de Educação Tecnológica. Nesse mesmo período são criados os Paramentos Curriculares Nacionais (PCN's) objetivando um ensino mais dinâmico e crítico em todas as disciplinas. Em 2008, é criada a Rede Federal de Educação Profissional, Científica e Tecnológica, objetivando uma educação integral, unindo teoria e prática para uma formação 
omnilateral. Assim a educação física tem seu papel contribuir com a formação humana integral/omnilateral (Garcia et al., 2018; Viana, Oliveira, et al., 2020)

\subsection{Formação Humana Integral/Omnilateral}

De acordo com Paulo Freire, em uma educação na perspectiva humanista, tanto o professor quanto a aluno, são educador-educando, em todo o processo educacional ambos se formam (Freire, 1969; Freire, 2002; Viana, Fecury, et al., 2020). Na educação ocidental, a formação humana está relacionada a humanização do homem, pois é um ser que não nasce pronto, mais que precisa ser educado/humanizado, capaz de captar, compreender e agir de acordo com suas finalidades, aumentando sua consciência (Coêlho \& Guimarães, 2012; Freire, 1996; Severino, 2006).

Uma formação integral promove a visão crítica da sociedade e um acesso ao conhecimento científico. Para contribuir nesse processo, a educação física deixa de lado uma tendência tecnicista ou esportivista, e passa entender o aluno como um sujeito temporal-histórico, assim partindo de uma reflexão das práticas da cultura corporal, possibilitando a capacidade do aluno em questionar a realidade (Viana, Fecury, et al., 2020).

Para a formação integral do sujeito, que tenha uma criticidade e que conheça as várias formas de comunicação, o movimento humano deixa de ser compreendido como algo natural do homem ou apenas mecânico e começa a ser tratado no aspecto histórico-cultural (Athayde, 2016; Balbino \& Urt, 2018).

Dessa forma, quando se tratando do termo integral pode-se adotar significado e sentindo de acordo com o contexto social e teoria que está sendo empregada (Lizzi \& Favoreto, 2018). No Brasil, a formação integral, já teve perspectivas diferenciadas: católica; anarquista; integralistas e liberais. Assim, Igualdade, liberdade, nacionalismo, pensamento-conservador, já foram característica de uma formação integral (Cardoso \& De Oliveira, 2019; Duarte \& Jacomeli, 2017) Ou seja, a formação integral pode está a favor do poder hegemônico, do capitalismo. Sendo oposto da Formação Omnilateral, uma vez que a formação total do homem nessa perspectiva supera os limites dados pelo capitalismo, busca-se a transformação social (Lizzi \& Favoreto, 2018).

O termo Omnilateral não foi inventado recentemente e não é uma palavra para substituir ou ser sinônimo do termo Integral. A formação omnilateral aparece pela primeira vez, em 1844, nos Manuscritos econômico filosóficos de Karl Marx onde a definição do tornar-se homem consiste em suas relações objetivas com o ambiente (Marx, 2004). Para Marx, uma formação omnilateral consiste em: 1) Educação intelectual; 2) Educação corporal; 3) Educação tecnológica (Marx \& Engels, 2011)

A perspectiva omnilateral é uma possiblidade de desenvolvimento total de cada ser humano, de todas as suas capacidades junto com suas relações sociais. É lutar para superar as desigualdades e as injustiças da sociedade, da educação e da cultura, para que todos tenham acesso (Baczinski \& Comar, 2019; Santos \& Santos, 2020)

A educação física já estava sendo apontada como um meio para uma formação global. A ideia de sujeito social-histórico deve fazer parte das aulas dessa disciplina, extrapolando o ser biológico, passa a ser social, histórico e cultural. Dessa forma, o aluno interpreta os signos que são produzidos, indo além movimentos, entende os saberes que componham a cultura corporal de movimento. Entendendo o corpo como resultado do processo histórico produzido pelo homem, promove uma relação com outras áreas do saber do campo educacional, inovado na práxis pedagógicas dessa componente escolar (Baczinski \& Comar, 2019; Batista, 2014; Duarte, 2014)

Para uma formação omnilateral, faz-se o uso da pedagogia histórico-critica, que tem como base filosófica o materialismo histórico-dialético, que é um método de análise para uma reflexão além da aparência. A pedagogia histórico-crítica torna o ensino significativo para os alunos, uma nova forma de pensamento que possibilita mudança de comportamento, que tenha uma posição em situação de injustiça e outras atitudes conscientes em sociedade (Gasparin \& Petenucci, 2014; Lizzi \& Favoreto, 2018). 
A cultura corporal faz parte da formação humana omnilateral, não se tem a divisão entre corpo e mente. Trabalhando a totalidade de cada tema da cultura corporal, contribui para os sentidos, emoções, identidades, e uma criação entre o intelectual e prática (Baczinski \& Comar, 2019; Viana, Fecury, et al., 2020)

\subsection{Sobre os Valores e Atitudes}

A formação omnilateral propõe um ensino para um homem-genérico, para isso, ocorre a união entre trabalho, ciência e cultura. Trabalho como princípio fundamental do ser humano e da prática econômica. A ciência que resulta em um conjunto de conhecimentos produzidos pelos homens. A cultura que está relacionada com os valores éticos e estéticos, esses que condizem normas de uma sociedade (Souza, 2014).

A educação profissional tem como objetivo uma formação que vai além da formação para o trabalho. Ou seja, uma formação ética-política, um sujeito que tenha em sua base o senso de justiça, igualdade, que opte pela verdade, entre outras atitudes para intervir e modificar a realidade social. Uma vez que a ética tem como fundamento a reflexão e a prática da liberdade(Santos, 2018).

Assim, como valores éticos, os estéticos são importantes. A estética não está restrita ao belo e sim à toda a forma de sensibilidade humana. Por meio dela o homem sai do estado bruto e desenvolve uma consciência, tornando-se um sujeito ético (Chaves \& Goergen, 2017).

A escola é um espaço formal de educação onde ocorre a defesa e socialização de valores e atitudes. No dia a dia escolar o professor, por meio de sua prática (na escolha de material, metodologia, abordagem), releva qual o ideal de formação que se deseja. Essa será expressada por valores e atitudes que são considerados corretos para atuar em sociedade. Dessa forma, ao perceber que vivemos em uma sociedade onde as contradições estão presentes os valores e atitudes podem ser reforçados ou problematizados (Freire et al., 2010; Guimarães et al., 2001; Neu et al., 2012; Souza, 2016). Ao elaborar as aulas, o professor tem em mente qual o tipo de aluno que atuara em sociedade, a partir de uma visão de mundo que será construída no processo educacional. O professor de educação física nessa perspectiva não pode adotar uma atitude de técnico/treinador, e sim de educador, para tal o docente tem que mudar sua pratica e concepções de ensino-aprendizagem (Gutierrez, 2008). As atitudes são condizentes com a equidade entre o falar e o agir do indivíduo (Brasil, 1997).

No instituto federal, a educação física como base a formação omnilateral trabalha com determinantes sociais, para uma visão de mundo além da aparência. Ela visa a autonomia e a autocrítica, proporcionando conhecimento aprofundado sobre as práticas (Silva et al., 2015)

Para superar a educação física tradicional, as aulas de educação física são tematizadas dentro de um contexto social, utilizado a teoria crítica como fundamento. Ao final, o aluno entenda sobre os direitos humanos, evite qualquer tipo de preconceito e discriminação, cada aula é um momento de reflexão e vivência de valores e atitudes (Acedo, 2009; Sá, 2019).

O objetivo geral deste estudo foi verificar a percepção do discente da educação profissional e técnica federal acerca do papel da educação física em sua formação integral e humanizada.

\section{Metodologia}

A pesquisa é de natureza aplicada e faz-se o uso de uma abordagem mista, através de questionário estruturado. Nesta abordagem ocorre a combinação de métodos, conceitos ou linguagem da pesquisa qualitativa e quantitativa (Paranhos et al., 2016). Ao utilizar ambas as abordagens, pode-se contribuir para as potencialidades de cada uma, resultando na compensação das deficiências ou limitações destas. Além disso propicia que o pesquisador tenha respostas mais abrangentes em relação a sua pesquisa (Dal-Farra \& Lopes, 2013). 


\subsection{Local da Pesquisa e Amostra}

A pesquisa foi conduzida no Instituto Federal de Educação, Ciência e Tecnologia do Amapá (IFAP), Campus Macapá (localizado a Rodovia Br-210 sn, Brasil Novo - AP, 68909-398) e Campus Santana (localizado a Rod. Duca Serra - Distrito Industrial, Santana - AP, 68925-000), no estado do Amapá. Foi escolhido para local de aplicação da pesquisa pois todos os cursos técnicos do ensino médio integrado possuem em sua grade curricular a disciplina de educação física.

A amostra foi formada por demanda espontânea para a pesquisa. Oitenta e oito (88) discentes, de ambos os sexos, com idades entre 15 e 18 anos, se despuseram a responder ao questionário da pesquisa (Tabela 1). Os discentes pertencem aos segundos anos dos cursos técnicos de nível médio, na forma integrada, vinculados ao Instituto Federal de Educação, Ciência e Tecnologia do Amapá, campus Macapá e campus Santana, no ano de 2021.

Tabela 1 - Mostra as porcentagens da amostra quanto ao curso, sexo biológico e faixa etária.

\begin{tabular}{|c|c|}
\hline \multicolumn{2}{|c|}{ CURSOS (2 ANO TÉCNICO) } \\
\hline Técnico em publicidade & $3.41 \%$ \\
\hline $\begin{array}{l}\text { Técnico em Redes de } \\
\text { Computadores }\end{array}$ & $11.36 \%$ \\
\hline Técnico em Química & $17.05 \%$ \\
\hline Técnico em Alimentos & $32.95 \%$ \\
\hline Técnico em Edificações & $35.23 \%$ \\
\hline \multicolumn{2}{|c|}{ SEXO BIOLÓGICO } \\
\hline MASCULINO & $38.64 \%$ \\
\hline FEMININO & $61.36 \%$ \\
\hline \multicolumn{2}{|l|}{ FAIXA ETÁRIA } \\
\hline 15 & $1.14 \%$ \\
\hline 18 & $7.95 \%$ \\
\hline 16 & $12.50 \%$ \\
\hline 17 & $78.41 \%$ \\
\hline
\end{tabular}

Fonte: Autores (com base nos dados da pesquisa).

Foram incluídos na pesquisa discentes estejam cursando o segundo ano ensino médio integrado no Instituto Federal de Educação, Ciência e Tecnologia do Amapá, no campus Macapá ou no campus Santana em 2021, e que se dispuseram a responder ao questionário.

Foram excluídos os discentes das demais formas e modalidades de ensino como: Técnico Subsequente; Técnico Concomitante; Proeja - Programa Nacional de Integração da Educação Profissional com a Educação Básica na Modalidade de Educação de Jovens e Adultos; e cursos de graduação. Foram também excluídos os discentes que não demostraram interesse em serem sujeitos da pesquisa (respondendo o questionário).

\subsection{Aspectos Éticos}

A pesquisa seguiu as recomendações do Comitê de Ética em pesquisa (CEP) Resolução n510, de 07 de abril de 2016 e Resolução nº 446, de 12 de dezembro de 2012 (Brasil, 2013), sendo analisada e com parecer favorável CAAE ${ }^{\circ}$ 36644820.1.0000.0001.

\subsection{Coleta de Dados}

Para a coleta de dados, fez-se o uso de questionário estruturado fechado, com a maioria das questões em escala Likert adaptadas de vários estudos (Costa, 2009; Feitosa, 2008; Nolasco, 2007; Oneto, 2013; Ribeiro et al., 2015; Silva, 2011) As 
questões submetidas aos participantes tiveram o objetivo de obter informações em relação ao objeto de estudo da pesquisa (Severino, 2006). Desta forma foram coletadas informações de uma pessoa ou de um grupo sobre valores, atitudes, fatos, sentimentos, interesses, comportamento, expectativas e motivações (Chaer et al., 2011; Cruz et al., 2018).

O questionário foi aplicado através da plataforma online Google Forms. A vantagem da utilização desta plataforma para pesquisa se deve a praticidade no processo de coleta das informações. O pesquisador enviou via e-mail ou através de um link, assim todos puderam responder de qualquer lugar (Mota, 2019).

\subsection{Análise Estatística}

Para a análise foi utilizado teste alfa de Cronbach, que é uma medida estatística de consistência interna que pode ser aplicada a questionários (Alves et al., 2021)

A escala de confiabilidade para o Alfa de Cronbach, adaptada de Lima (2018), mede a consistência interna do questionário aplicado e está distribuída segundo a Tabela 2 (Landis \& Koch, 1977; Lima, 2018).

Tabela 2 - Mostra a escala de confiabilidade do teste Alfa de Cronbach.

\begin{tabular}{c|c} 
Confialbilidade - Alpha de Cronbach \\
\hline Quase Perfeita & entre 0,81 e 1,0 \\
Substancial & entre 0,61 e 0,80 \\
Moderada & entre 0,41 e 0,60 \\
Razoável & entre 0,21 e 0,40 \\
Pequena & 0,20 ou menor \\
\hline \multicolumn{2}{c}{ Fonte: Adaptado de Lima (2018) }
\end{tabular}

Para análise da confiabilidade, a consistência interna foi avaliada a partir do coeficiente Alfa de Cronbach ( $\alpha$ ) no programa IBM® SPSS ${ }^{\circledR}$ PASW Statistics 18 . O resultado retornou uma consistência interna substancial no questionário utilizado $(\alpha=0,746)$ (Tabela 3$)$.

Tabela 3 - Mostra o resultado estatístico da confiabilidade (consistência interna) do questionário utilizado.

\begin{tabular}{c|c|c}
\hline \multicolumn{2}{c}{ ESTATÍSTICAS DE CONFIABILIDADE } \\
\hline $\begin{array}{c}\text { Alpha de } \\
\text { Cronbach }\end{array}$ & $\begin{array}{c}\text { Alpha de Cronbach } \\
\text { baseado em itens } \\
\text { padronizados }\end{array}$ & $\begin{array}{c}\text { Número de } \\
\text { Itens }\end{array}$ \\
\hline 0,746 & 0,768 & 50 \\
\hline
\end{tabular}

Fonte: Autores.

\section{Resultados e Discussão}

\subsection{A percepção do Discente perante papel do Docente}

A porcentagem de repostas sobre a contribuição do professor de educação física em relação a respeito próprio do aluno e ao próximo aparece na Figura 1. Há uma pequena diferença entre as respostas "nenhum" e "pouco", respectivamente $6.82 \% \mathrm{e}$ 5.68\%. Dos participantes $15.91 \%$ responderam "médio" e $42.05 \%$ responderam como "muito importante". Outros $29.55 \%$ consideram a contribuição do professor como "importante". 
Figura 1 - Porcentagem de repostas sobre a contribuição do professor de educação física em relação a respeito próprio do aluno e ao próximo.

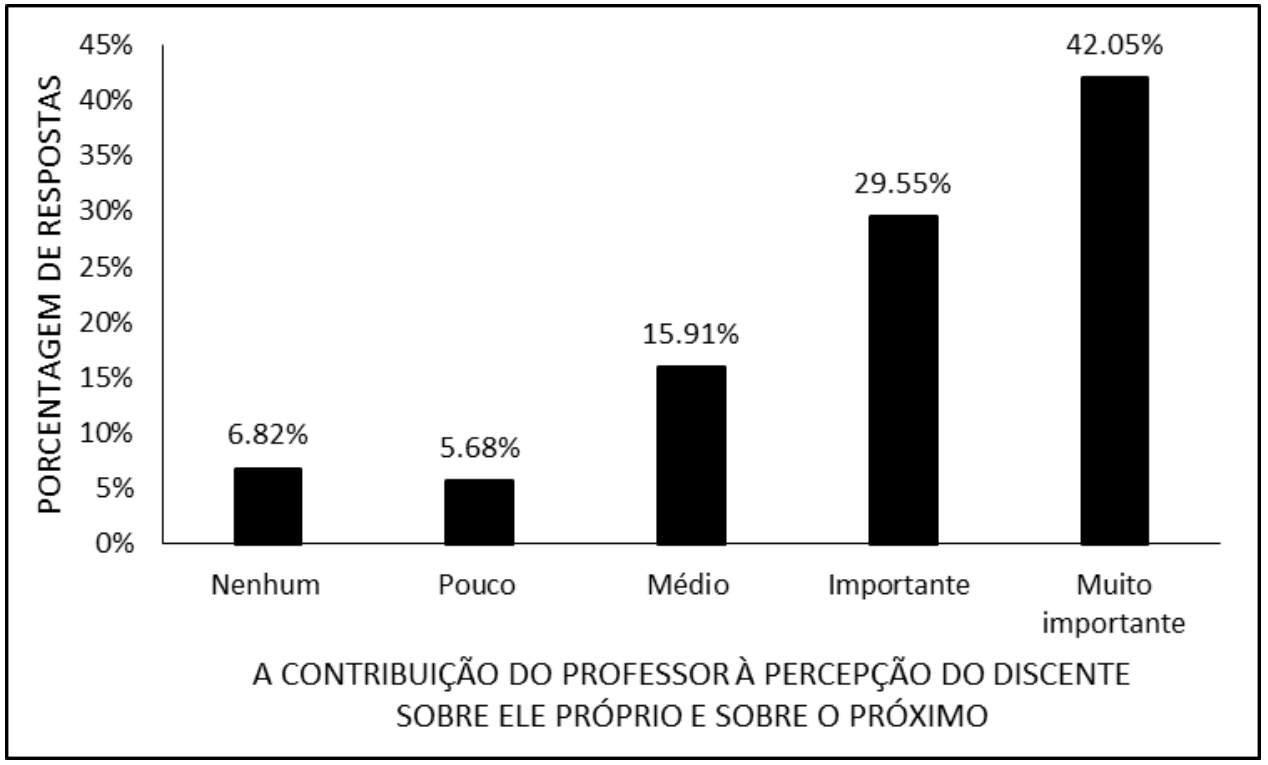

Fonte: Autores.

A educação está pautada na formação do homem, esse processo é inerente ao sujeito que ao mesmo tempo é social e histórico. Ter uma percepção de si e do próximo faz parte desse processo de formação, nesse aspecto os alunos consideram como importante ou muito importante a contribuição do professor. O aluno está em uma busca e construção da sua imagem, identidade, a construção ocorre ao longo do tempo de forma inconsciente e sendo formada constantemente, nunca finalizada, com isso esse educando necessita ser ouvido, ser reflexivo e ter uma compressão sobre a sua realidade e a sociedade (Brait et al., 2010; Monteiro, 2017)

Segundo Monteiro (2017) o professor de educação física tem que refletir sobre a sua prática pedagógica para trabalhar de forma adequada a visão que o aluno tem dele e dos outros, dando uma característica transformadora.

Segundo Beggiato (2009) o docente deve manter em sua mente o compromisso político e filosófico em seu trabalho, e quando se trata dos preceitos técnicos deve ter um cuidado com a dimensão humanística interacional, assim, construindo um campo onde tanto o professor quanto o aluno possam desenvolver diálogos e trabalhos que consideram a expressão do aluno, sendo esse o requisito básico para avançar em relação onde se está e para onde quer chegar.

Apenas uma pequena percentagem não reconheceu a contribuição do professor de educação física, repostas como "pouco" e "médio" sinalizam que os alunos têm em mente qual o papel do docente, mesmo que essa noção não esteja bem clara para os educandos. Quando se fala da percepção de si e do próximo o que está sendo trabalhada é a representação social, que está dentro de um contexto histórico e cultural, e que define a identidade e a expressão como um ser social de cada sujeito. Esse conhecimento dá sentindo e contexto para a vida do aluno, dando a ele e aos outros uma noção da realidade. São assuntos que vão despertar a curiosidade, o questionamento e a necessidade de expressar seu ponto de vista pessoal. Dessa forma um novo conhecimento, que vai fazer um novo sentindo em diversos locais e momentos do dia a dia, vai sendo construído. (Beggiato, 2009).

A porcentagem de repostas sobre aproveitamento dos conhecimentos trazidos pelos alunos na Figura 2 mostra que $0,00 \%$ “discorda fortemente", em seguida 1.14\% “discordam”, já 17.05\% dizem "não ter uma opinião a respeito", em sequência $18.18 \%$ "concordam fortemente" e $63.64 \%$ "concordam" que o professor aproveitasse o conhecimento prévio do aluno. 
Figura 2 - Porcentagem de respostas sobre o professor aproveitar o conhecimento prévio do aluno de acordo com sua vivência e incorporá-la as aulas

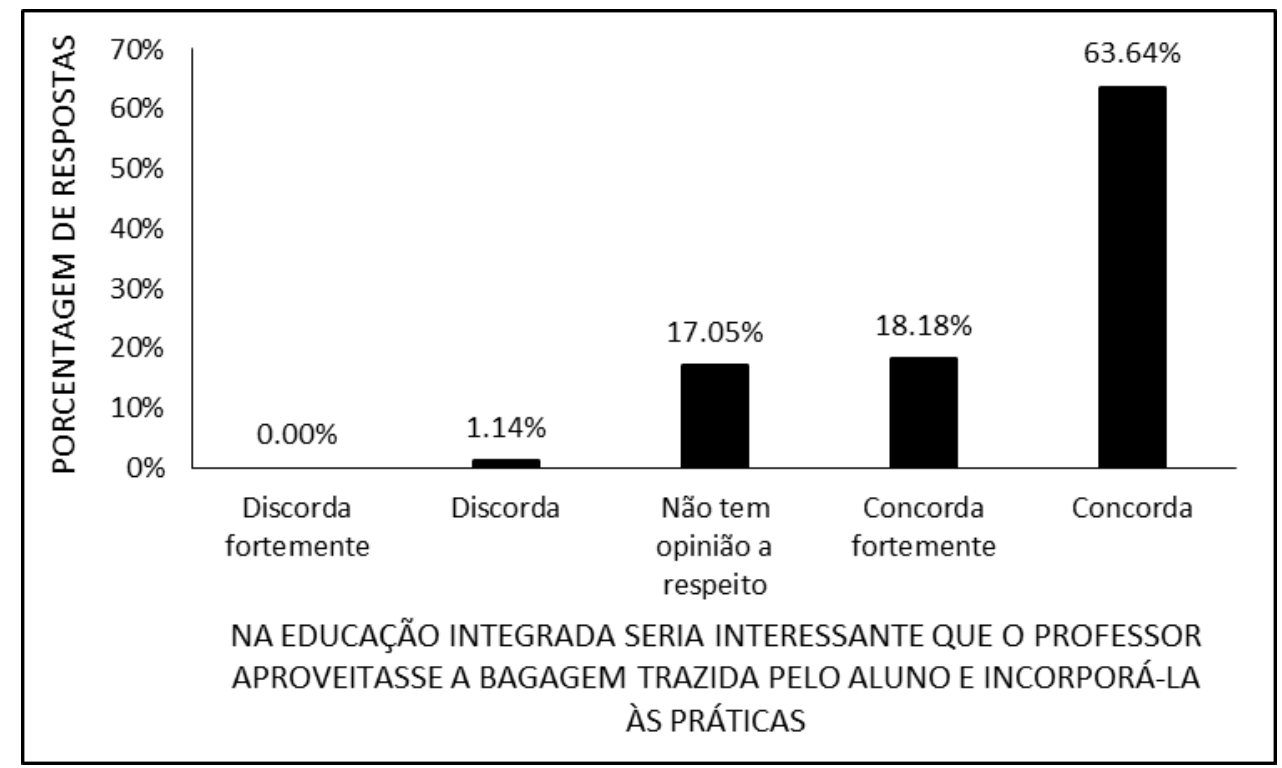

Fonte: Autores.

Os alunos acham interessante que o professor trabalhe em sala de aula os saberes que cada um traz de sua vivência. Segundo Brait et al. (2010) o aluno tem consigo uma gama de informações que se o professor souber aproveitar corretamente, seus alunos poderão ter um grande sucesso no processo de ensino-aprendizagem.

Freire (1996) defende que no ato de ensinar, o conhecimento do aluno deve ser respeitado. Quando se aproveita os saberes dos educandos, pode-se discutir diversas situações que se fazem presentes nas práticas corporais como a diferença entre violência e lutas; vivência e discussão sobre a segregação de gênero no esporte; e se o local onde vivemos possibilita manter uma vida saudável. Quando se considera as múltiplas realidades, Brait et al. (2010) explica que o aluno, ao ter seus saberes como parte da pratica pedagógica se sente contemplado, motivando-o para as participações nas aulas, uma vez que o prazer em aprender não é espontâneo, sendo vista as vezes como uma obrigação.

Aqueles que responderam "discordam” ou "não tenho opinião a respeito ", possivelmente ainda percebem a educação física como um momento de descanso ou como momento qualquer. Nesse sentido Sá (2019) diz que os alunos do ensino médio ainda enxergam a educação física com pouca importância, acrítica, sendo isso resultado das experiências dos alunos durante o ensino fundamental.

Na Figura 3, ao abordar sobre a relação aluno-professor, com 2.27\% responderam como "péssimo”, em seguida com $4.55 \%$ como "ruim", dando um salto significante, $26.14 \%$ consideram "excelente" e $45.45 \%$ como "boa" a relação com o professor nas aulas de educação física. 
Figura 3- Porcentagem de repostas sobre a relação aluno-professor durante as aulas de educação física.

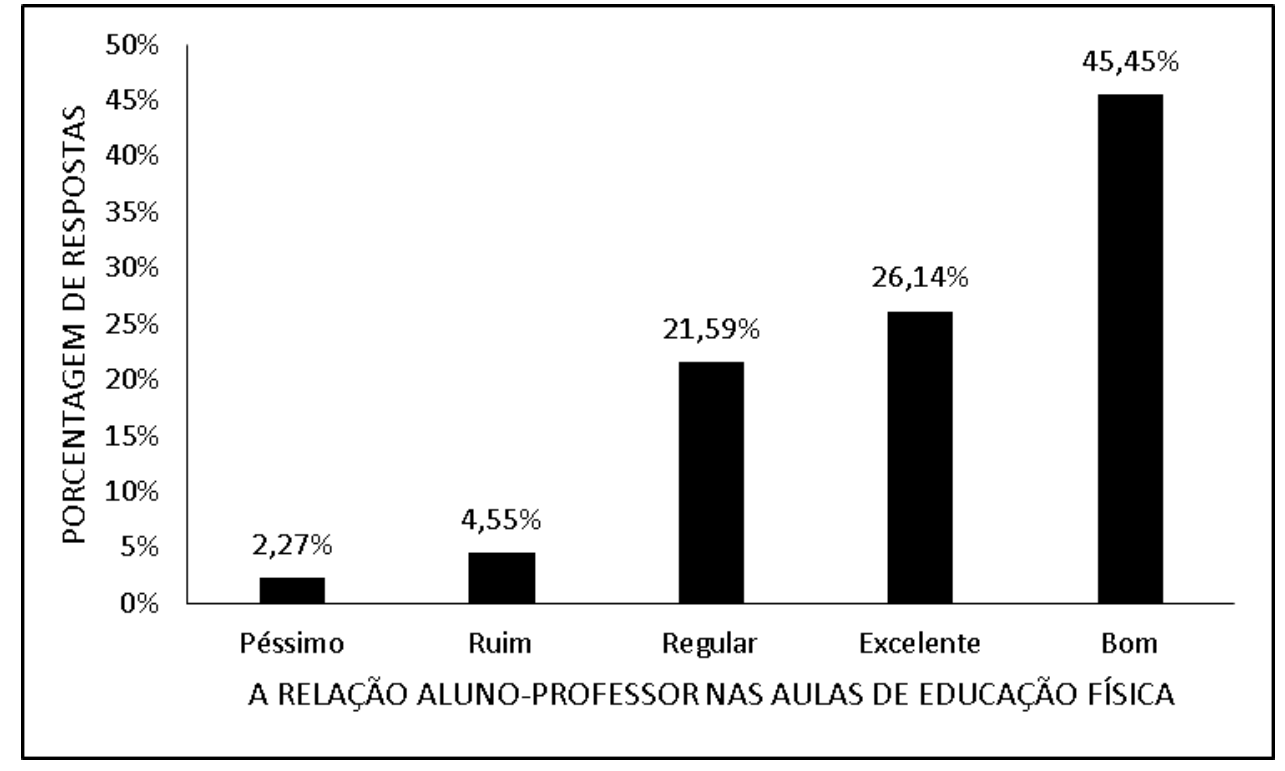

Fonte: Autores.

Ao se tratar sobre a relação aluno-professor, a maioria dos respondentes consideram essa relação como "boa", tendo uma diferença de 4.55\% entre as respostas como "excelente" e "regular". De acordo com Martinelli et al. (2006) o nível de satisfação da relação do aluno com o professor pode ser um forte motivo para a participação ou não deste nas aulas de educação física. O professor deve achar soluções para motivar os alunos a participarem das aulas. O docente do ensino médio precisa mudar sua atitude para lidar com os alunos mais críticos e até com os desmotivados.

Os números ligados a péssimo, ruim e regular, pode ter relação com a motivação desses alunos, ou na sua forma de lidar com as práticas proporcionadas pelo professor, vale lembrar que os educandos do ensino médio estão em um processo de transformação corporal, psicológica e social. Um aluno pode recusar-se de participar da aula por alegar que não quer ficar suado, por questões hormonais, por achar que não tem habilidades, entre outras alegações. A falta de habilidade docente em contornar essas problemáticas pode impactar de forma negativa sua relação com os alunos. Esta relação está além do ensino de conteúdo e habilidades, envolvendo aquisição de valores, atitudes, hábitos e motivação, aspectos que vão refletir na aprendizagem do aluno (Brait et al., 2010; Monteiro, 2017).

Quando se trata da relação aluno-professor, o discente procura algo além das habilidades e conteúdo. Ele busca ter um afeto, um acolhimento. Em muitos momentos, sem perceber, ele sente prazer em práticas onde o cognitivo e processo vital estão unidos (Silva, 2019).

Ainda sobre o papel do docente, na Figura 4, quando perguntados se o professor estimula o senso crítico em relação ao esporte e as atividades físicas, $2.27 \%$ responderam que "discorda muito", logo depois com 4.55\% "discordam", uma pequena parcela com $11.36 \%$ mostrou que "está em dúvida”, já mostra um consenso entre os respondentes quando $20.45 \%$ “concorda muito" e 51.36\% "concorda" que sim, o docente trabalha de forma critica o esporte e as atividades físicas. 
Figura 4 - Porcentagem de respostas se o professor estimula o senso crítico em relação ao esporte e às atividades físicas.

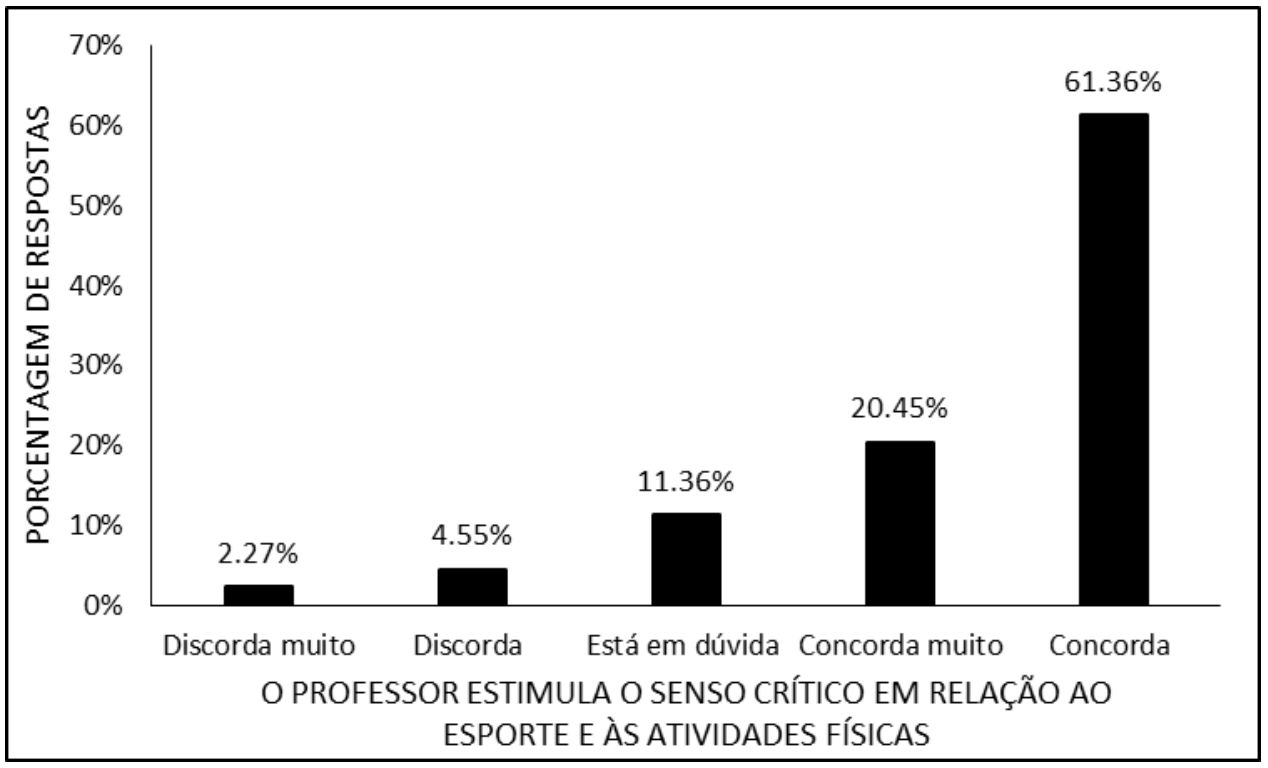

Fonte: Autores.

A maioria reconhece que o professor estimula uma visão crítica em relação ao esporte e as outras atividades físicas. Ter essa criticidade permite que o aluno entenda o esporte e outras atividades além dos seus mitos. Entenda o motivo em aderir a uma atividade física, e não por ser apenas a pratica do momento. Estando de acordo com essa ideia, Júnior et al. (2019) diz que na dimensão educacional é importante ter uma leitura contextualizada do que seria o esporte no mundo contemporâneo, tendo a função e compromisso de leitura, análise, interpretação da realidade. Para essa análise há diversas temáticas dentro desses fenômenos sociais complexos presentes, como exemplo: Dominação ideológica, diversidade e inclusão, globalização, identidade, corporeidade e entre outros.

Na Figura 5, quando questionados sobre o estimulo a trabalho em equipe e respeito as suas limitações, a porcentagem em três repostas foi bem baixa, sendo $2.27 \%$ "discordam muito", logo depois com 3.41\% "discordam", e 5.68\% "estão em dúvida". As maiores respostas tiveram 35.23\% falando que "concordam" e 53.41\% responderam em "concordar muito", se o professor estimula o trabalho em equipe e respeita as imitações. 
Figura 5 - Porcentagem de repostas em relação ao estimulo do trabalho de equipe e respeito a limitações do aluno.

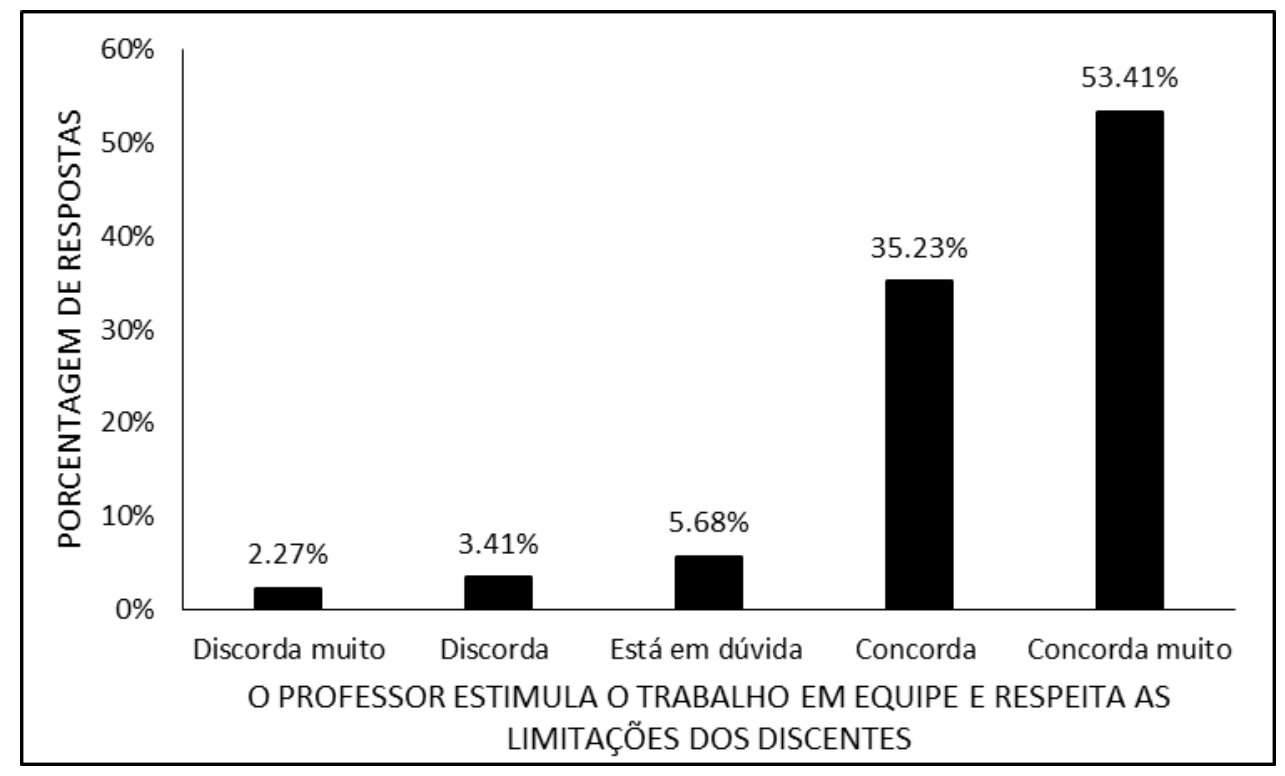

Fonte: Autores.

O resultado mostra que grande parte dos alunos reconhecem que o professor em suas aulas estimula o trabalho em equipe. Segundo Saraiva et al. (2017) o trabalho em equipe tem em sua essência o comprometimento e o coleguismo. Durante as aulas, onde corre o trabalho coletivo, aprende o esporte em si, também a conviver em grupo. Nessa relação, revela-se princípios éticos e morais que fazem parte da sociedade. durante as aulas de educação física de forma inconsciente os alunos estão se tonando aptos para adentrar qualquer ambiente e desenvolvendo a visão do que é certo ou errado.

Além do estimulo, o professor respeita os limites dos alunos. Os limites podem ser os mais variados possíveis como, por exemplo, a falta de habilidade motora ou a percepção sobre determinada pratica corporal segundo uma crença. O professor não pode ignorar as histórias e devem considerar a diversidade no momento de trabalhar os conteúdos da aula. Assim os alunos se apropriam dos conhecimentos e os utilizam para solucionar problemas (Rigoni, 2010).

Quando perguntados sobre o sobre o ensino de valores e cidadania nas aulas de educação física, a Figura 6 mostra que poucos discordam, quando tem-se $2.27 \%$ “discordam muito" e $7.96 \%$ responderam "discordam", em terceiro vem os $14.77 \%$ que "estão em dúvida", quando 31.82\% "concordam muito", e 43.18\% "concordam" revela que o processo ensinar valores e cidadania nas aulas. 
Figura 6 - Porcentagem de repostas sobre o ensino de valores e cidadania nas aulas de educação física.

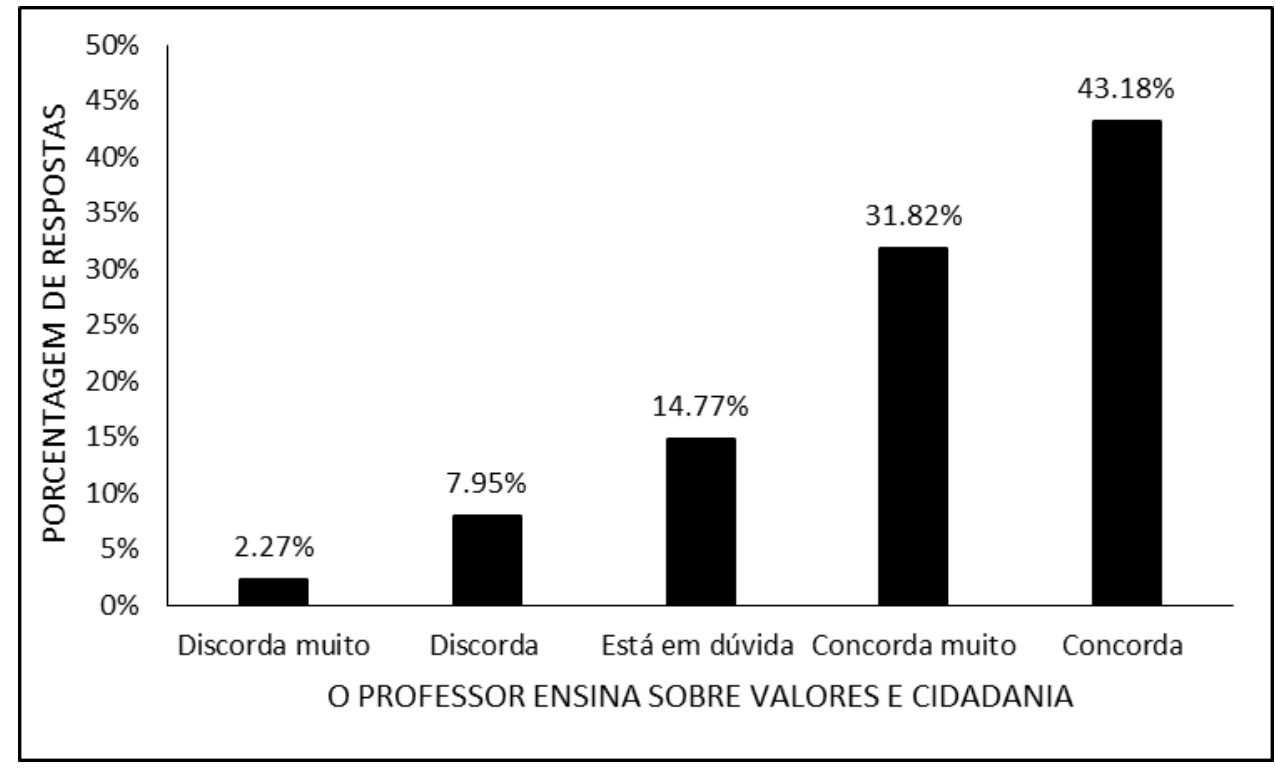

Fonte: Autores.

O aprendizado de valores, normas e atitudes ocorre no desenvolvimento da moral do homem. Podem ser aprendidos pela submissão (aceitos sem questionar), pela imitação (aprendidos através de uma identificação com o professor), pela internalização (por vontade própria com bases nas reflexões, sem uma obrigatoriedade na apresentação desse comportamento) (Dos Santos \& Freire, 2006).

Por meio do esporte, o professor pode ensinar valores e cidadania, já que essa pratica tem um potencial de socialização entre os praticantes, pois as diferenças estão presentes (classe, gênero, religião, entre outras). Em uma partida de futebol na quadra, vôlei na praça, basquete de rua, ocorre o fortalecimento de amizades, criação de novos vínculos (Bickel et al., 2012).

\subsection{A percepção do Discente sobre a Educação Física}

Quando questionados se os valores e atitudes presentes nas práticas competitivas trazem algo de educativo, a Figura 7 mostra a mesma porcentagem para as respostas "não têm opinião a respeito" e "certamente que não" ambas com $2.27 \%$, uma certa quantidade respondeu que "depende do professor" com 18.18\%, já 34.09\% responderam “as vezes” e $43.18 \%$ responderam que "certamente sim". 
Figura 7 - Porcentagem de repostas em relação aos esportes competitivos nas aulas de educação física, se os valores e atitudes presentes nas práticas trazem algo de educativo.

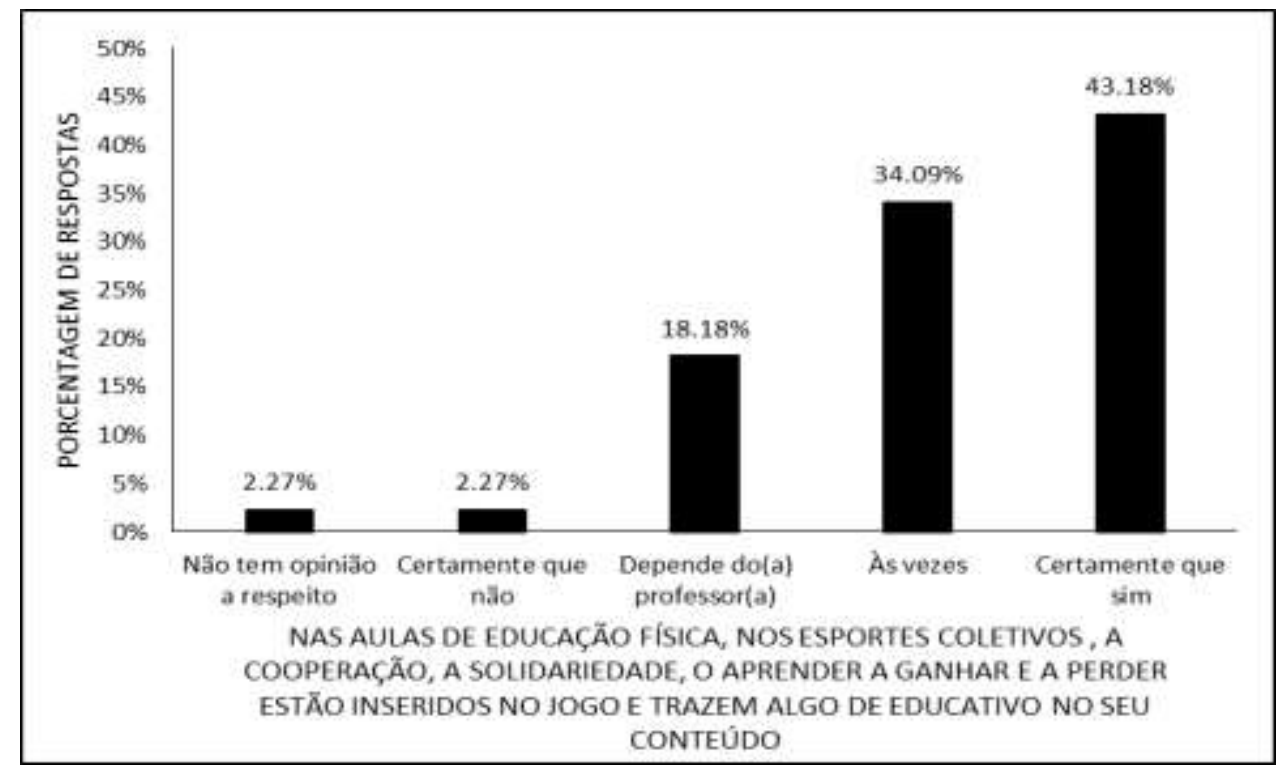

Fonte: Autores.

Como explanado no discursão da Figura 6, no esporte ocorre o compartilhamento de alegrias e tristezas, junto a isso, no esporte coletivo se tem a cooperação, solidariedade, entre outras atitudes (Bickel et al., 2012). Interessante notar que a maioria confirma que há algo de educativo, mas ao olhar para as porcentagens das repostas as "vezes" e "depende do professor", mostra que os alunos percebem que só terá algo educativo dependendo do planejamento do professor de educação física (Cardoso et al., 2011).

Isso mostra que o docente de educação física tem que ter mais uma postura de educador, e menos de um técnico em busca da perfeição e exposição de um ideal de execução. Visando uma formação humana omnilateral do aluno o professor deve abandonar o papel de técnico, mudar seu comportamento em relação a sua pratica e ideia de ensino-aprendizagem (Gallardo et al., 2003; Gutierrez, 2008).

O esporte é entendido como um fenômeno humano, mas essa característica não é o suficiente para que o sujeito compreenda o que é essa prática. Há uma diferença entre saber um esporte e saber exclusivamente praticar o esporte. Quando os alunos dizem que depende do professor fica evidente que o papel do professor é trabalhar o esporte coletivo como fenômeno social e oportunidade de aprendizagem corporal (Furtado et al., 2019).

Dentro dos esportes, seja coletivo ou individual, existe a competição e cooperação, quando perguntados se valorizasse a cooperação durantes as aulas de educação física, o momento dessas aulas melhoraria. De acordo com a Figura 8, dos respondentes 5.68\% "Não acreditam”, já 10.23\% "Não têm opinião a respeito”, em seguida 26.14\% responderam que "é isso que a educação física precisa" e 57.95\% acreditam que "a educação física precisa disso". 
Figura 8 - Porcentagem de repostas sobre a valorização da cooperação e não da competição nas aulas de educação física.

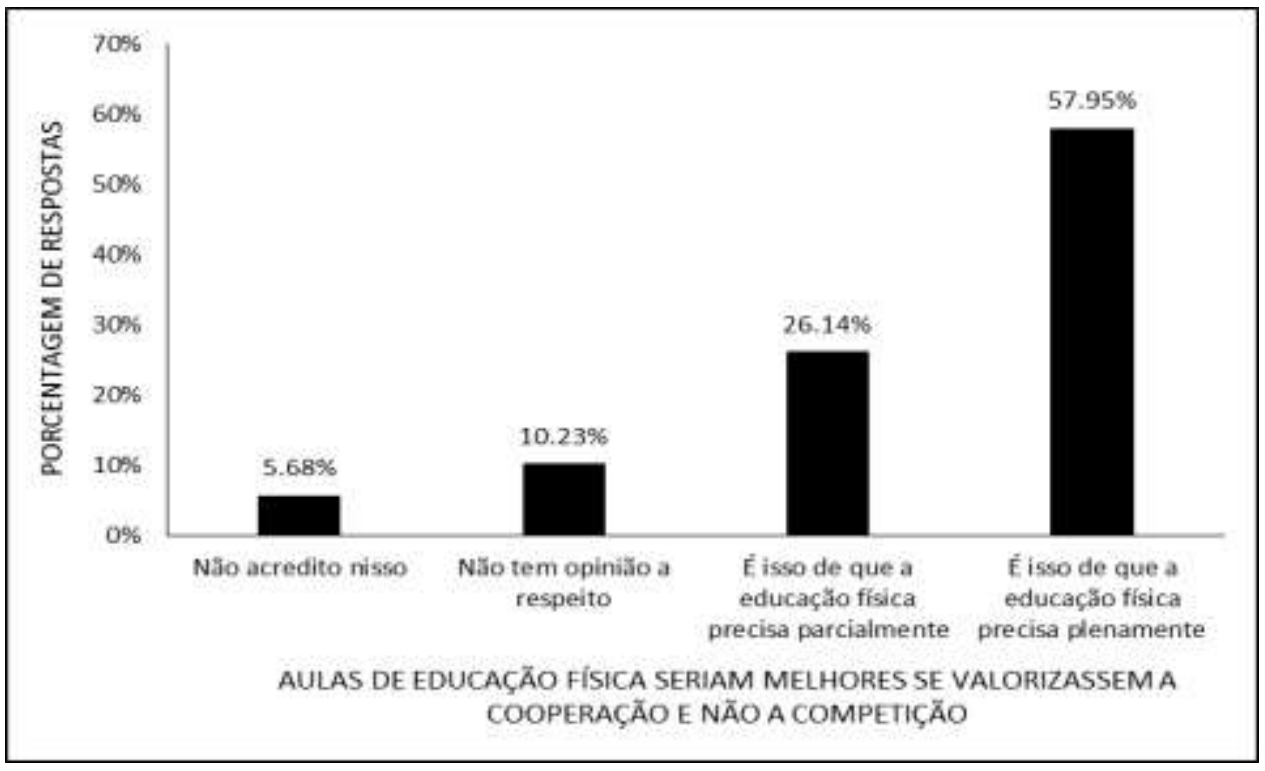

Fonte: Autores.

Entre as repostas "precisa parcialmente" e "precisa plenamente", nota-se que os alunos têm uma convicção total ou parcial sobre a valorização da cooperação. Sobre esse aspecto Bickel et al. (2012) frisa que durante as aulas o aluno precisa ter em mente que é saudável competir, que pode querer ser o melhor, o mais forte, o mais ágil, mas ao mesmo tempo que esse aluno entenda que é importante ajudar o próximo a ser tudo aquilo que ele também tem vontade, e que juntos podem ser melhores. Ao mesmo tempo que proporciona formação social e educacional, forma-se o caráter do aluno, a cooperação, o trabalho coletivo deve ser considerado para que exista o desejo de ajudar o outro ser o melhor.

Com a valorização da cooperação ocorre a integração dos alunos, tornando-se fundamental para um melhor desempenho e sucesso do educando. Antes existia a dificuldade que os alunos olhassem para as aulas tendo a participação como elemento mais importante, sem fazer das aulas uma disputa. Quando se trabalha em cooperação, é dado ao sujeito a oportunidade de conviver com os outros sem deixar de lado quem somos (Beggiato, 2009; Bickel et al., 2012).

Quando se trabalha com a cooperação o lúdico aparece junto com a afeto, isso torna o ambiente escolar familiar e oportuniza que o aluno se descubra. Sendo adotado de emoções e sentimentos, tem a necessidade de criar ou manter vínculos de amor e carinho em suas relações (Tavares et al., 2019).

Em relação ao lúdico, a Figura 9 mostra uma pequena porcentagem entre três respostas, a primeira com 1.00\% diz que "São atividades que só fazem passar o tempo", a segunda com $2.27 \%$ diz que "é muito pouco daquilo que pretendo", e a terceira com $2.27 \%$ diz que "Não é nada daquilo que eu pretendo", já com 37.50\% diz que "É parecido com aquilo que eu quero para mim" e 56.82\% como "É exatamente aquilo que necessitam". 
Figura 9 - Porcentagem de repostas sobre uma aprendizagem baseada no lúdico dentro das aulas de educação física.

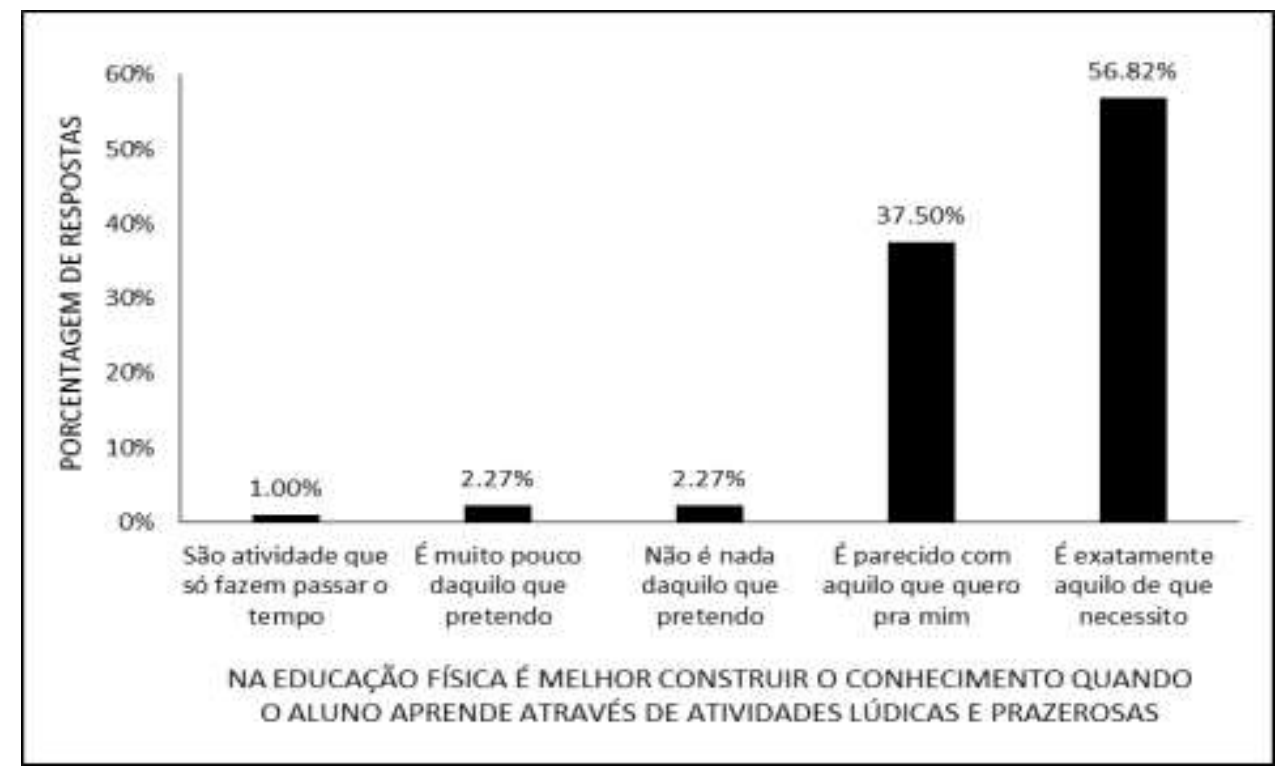

Fonte: Autores.

Grande parte dos alunos demostram que é melhor construir o conhecimento por meio do lúdico. Esse reconhecimento acontece porque as aulas tornam-se mais atrativas, proporcionando momentos de descontração. O professor por meio do lúdico desenvolve a criatividade, capacidade de decisão, desenvolvimento motor, assim como valores e noção de cidadania (Junior, 2013).

Quando o assunto é a formação do aluno, o lúdico contribui para a construção da personalidade, pois possibilita a integração da diversidade. Em relação a formação integral, o lúdico lida muito com os valores estéticos, traz uma ideia de reinvenção da inteligência, utiliza a imaginação para melhorar a capacidade de representação mental. Intervindo na realidade concreta de forma original e criativa para solucionar problemas, coloca na cultura, o lúdico, o equilíbrio da vida. Acontecendo pela pratica do querer, da imaginação durante as atividades em sala de aula (Junior, 2013; Sousa \& Simeoni 2014).

Sobre intervenção social, os alunos foram questionados se a educação física poderia ser usada como ferramenta de transformação social. Dos respondentes, $0.00 \%$ "Discordam fortemente", ainda uma pequena parcela discorda com $1.14 \%$ “Discordam", já 7.95\% diz "Não tem opinião a respeito", as opções "concordam” e "concordam fortemente” tiveram ambas $45.45 \%$ (Figura10). 
Figura 10 - Mostra a porcentagem de repostas sobre o ensino da educação física como ferramenta de transformação social, agregando o senso comum com o conhecimento cientifico.

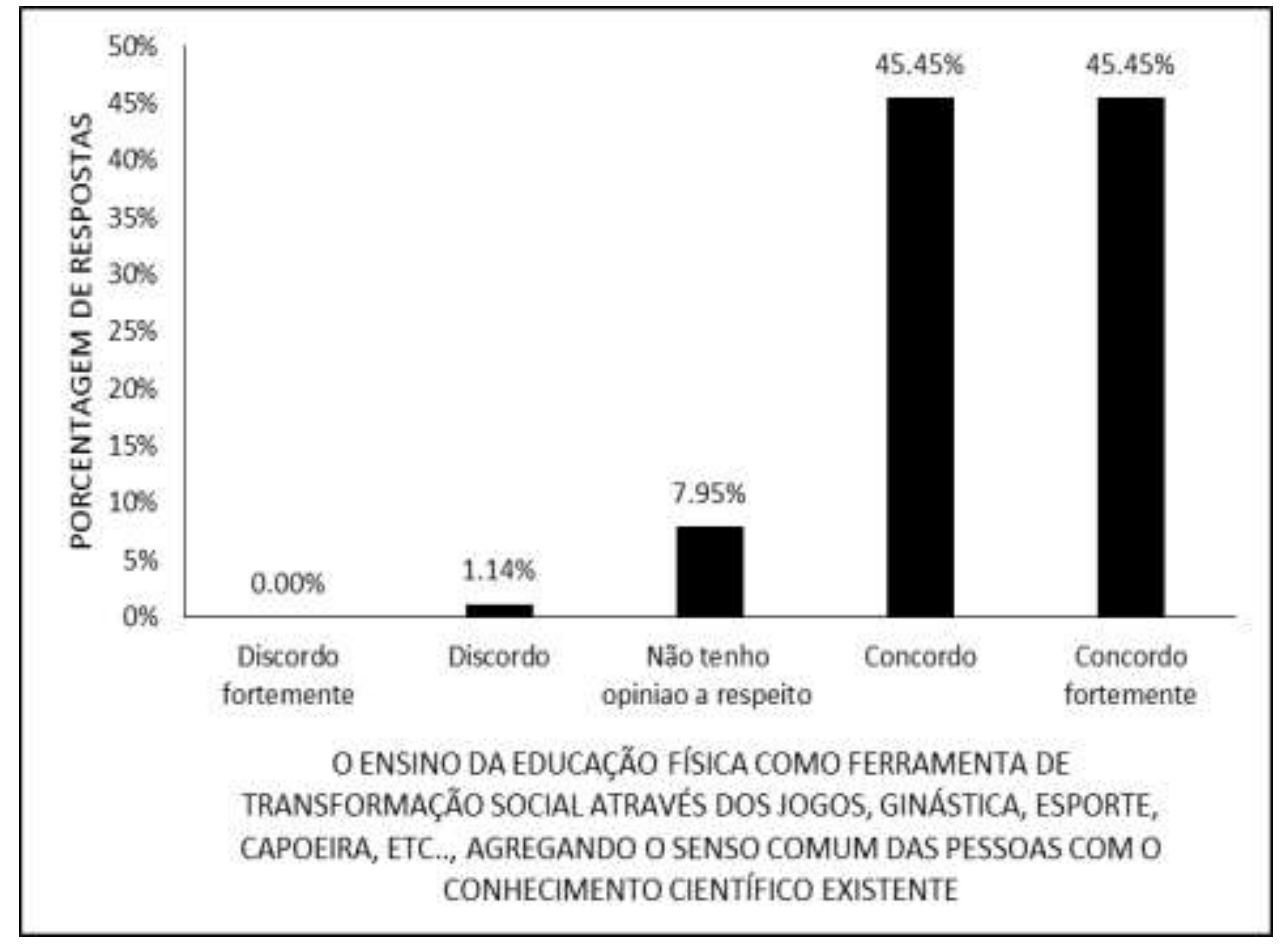

Fonte: Autores.

Os alunos concordam que a educação física pode ser usada para a transformação social. Essa perspectiva de educação está pautada na pedagogia histórico-critica (PHC). Para a PHC, o homem não nasce sabendo ser homem, então o ato de pensar, questionar, sentir, querer, agir e avaliar, é preciso ser aprendido. A escola existe para levar o aluno ao acesso de saberes mais elaborados (científicos), sem ignorar sua forma rudimentar. Então, o conhecimento trabalhado em sala será metódico, científico, prevalecendo sobre o saber comum, natural e assistemático (Haddad \& Pereira, 2013).

O papel do professor é importante nesse processo, uma vez que ele é o agente responsável pela organização pedagógica, que planeja a sequência, a forma adequada para apropriação dos saberes garantindo uma boa aprendizagem do aluno. O professor de educação física deve ensinar o que o aluno não consegue aprender sozinho, o docente dirige os conteúdos científicos que vão ocasionar a elevação do pensamento elaborado (Haddad \& Pereira, 2013).

Dessa forma, o resultado mostra que os alunos entendem que o ensino-aprendizagem para o desenvolvimento humano em sua totalidade, está na relação do sujeito e sociedade, mente e corpo, teoria e prática. Pensar na transformação da sociedade é entender que todos os homens têm o direito apropriação dos conhecimentos científicos, artísticos e filosóficos, levando o homem para uma formação omnilateral (Haddad \& Pereira, 2013)

Na educação física por muito tempo a corrente tecnicista predominou, até hoje ainda há professores que são aptos a essa abordagem. Na Figura 11, quanto ao uso dessa corrente nas aulas de educação física, com 5.68\% diz que "Não acham importante e não concordo", em seguida com 5.68\% "Para mim tanto faz", já com 10.23\% "Não tenho opinião a respeito", dos respondentes $19.32 \%$ “acham importante pois a vida é uma eterna competição" e 59.09\% “acham parcialmente importante. 
Figura 11 - Mostra a porcentagem de repostas sobre o uso da corrente tecnicista nas aulas de educação física

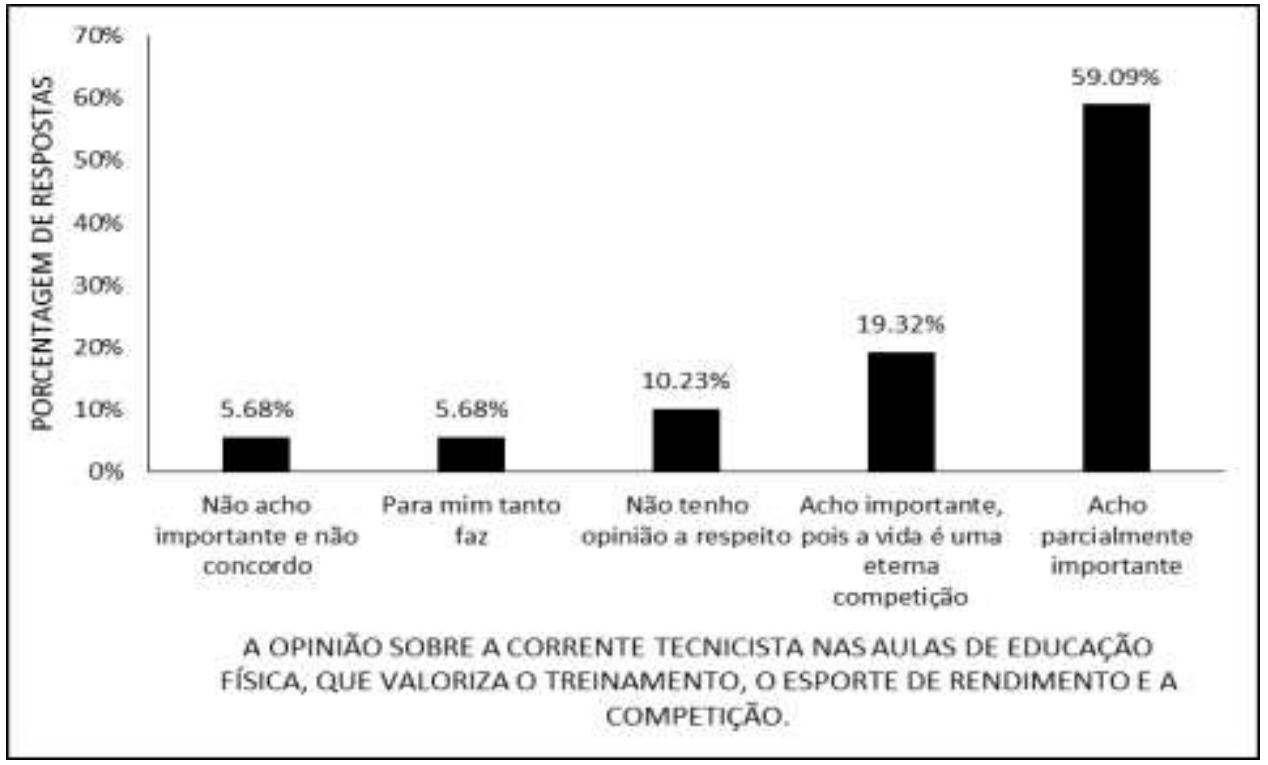

Fonte: Autores.

Nessa visão mais tradicional, praticar um esporte significa que antes tem-se que fazer e dominar o gesto técnico. Ou seja, o ensino das modalidades ocorre de forma fragmentada por etapas e descontextualizada da realidade, o aluno só tem contado com a pratica quando apresentar uma evolução e domínio da técnica (Daolio, 2002).

Os alunos acham parcialmente importante, uma justificativa para isso seria em não querer ter uma aula puramente técnica. Levando em consideração apenas o gesto técnico pode causar afastamentos dos alunos, aqueles que apresentam uma dificuldade motora pode apresentar um desinteresse no futuro. Dessa forma, nessa abordagem ocorre a exclusão, seletividade e valorização do esporte de alto rendimento (Finck, 2011).

Sobre os alunos que acham importante porque a vida é uma eterna competição, segundo Junior (2013) o educando do ensino médio em grande parte só vem praticando as quatro modalidades esportivas. Essa visão de competição é o auge na idade deles, uma vez que geram competição na forma de se arrumar, comportar-se, chamar atenção, ter as melhores notas. E isso acontece nas práticas onde o aluno quer vencer a qualquer custo, deixando de lado qualquer valor e atitude importante para o convivo em sociedade.

O professor deixa de lado a postura de técnico, pois se um educador causar um impacto negativo em relação a prática de atividade física pode ser considerado como uma irresponsabilidade pedagógica. Mostrando um reflexo, o estudo de Ladwig et al. (2018) diz que a relação do aluno com a educação física na escola pode estar relacionada com uma vida mais sedentária na vida adulta. Aqueles que tem memórias desagradáveis tem uma maior resistência apara ser adapto de uma atividade física. Já aqueles que afirmam em gostar de alguma atividade no fim de semana apresentaram ter ótimas lembranças das aulas de educação física. Sendo assim, o uso da técnica tem que ser pensado para facilitar e estimular a vivencia de movimentos que tenha significados para cada aluno (Furtado et al., 2019).

\subsection{A percepção da importância da Educação Física na Formação Discente}

Sobre a importância da educação física no ensino médio técnico $87.50 \%$ responderam que "sim" e $12.50 \%$ "não" acham importante ter aulas de educação física no ensino técnico. 
Tabela 4 - Porcentagem de repostas sobre a consideração dos discente da importância das aulas de educação física no ensino médio técnico.

\begin{tabular}{|c|c|}
\hline \multicolumn{2}{|c|}{$\begin{array}{l}\text { O DISCENTE CONSIDERA IMPORTANTE TER AULAS } \\
\text { DE EDUCAÇÃO FÍSICA NO ENSINO TÉCNICO }\end{array}$} \\
\hline SIM & $87.50 \%$ \\
\hline NÃO & $12.50 \%$ \\
\hline
\end{tabular}

Fonte: Autores.

O ensino médio técnico tem como princípio articulação dos conhecimentos científicos das diversas áreas do conhecimento, indo além da preparação para o mercado de trabalho, que o aluno tenha ferramentas para uma intervenção consciente e crítica na realidade (Minuzzi et al., 2019)

Tratando-se do ensino médio integrado, fala-se do tipo de sujeitos que serão formados, ou seja, o objetivo é um sujeito que tenha uma característica de formação humana omnilateral. Tendo o trabalho, ciência, tecnologia e cultura como eixos, a educação física pode contribuir com cada eixo (Marcolino \& Lima, 2019).

A educação física na EPT é uma componente curricular importante, pois ela tem uma alta capacidade de contribuir para uma formação integral. Para isso o professor tem que planejar práticas pedagógicas da Educação Física que estejam de acordo com os pressupostos da formação omnilateral (Souza \& Benites, 2021).

A experiência nos anos anteriores no ensino fundamental pode influenciar a visão e a relação do aluno com a educação física no ensino médio. A porcentagem de alunos que dizem não ser importante pode ser um reflexo de suas vivências. A ausência de uma proposta de educação física de intervenção ou de organização curricular tem levado a limitar as aulas em algumas modalidades esportivas e saberes sobre lazer. Essa característica é contrária ao papel da educação uma vez que a pratica pedagógica tem como objetivo provocar e reconstruir saberes, atitudes e formas de conduta (Almeida \& Martins, 2020).

Depois de responderam se a educação física era importante na EPT, os alunos responderam se a educação física é importante para a formação do cidadão. Desses, 4.55\% "Uma coisa não tem nada a ver coma outra", 5.68\% diz "Não têm opinião a respeito", já 10.23\% diz "Não", em seguida com 12.50\% "Depende do professor" e 67.05\% responderam que "claro que sim" (Figura 12). 
Figura 12 - Porcentagem de repostas sobre a consideração dos alunos em relação a importância da educação física para sua formação como cidadão.

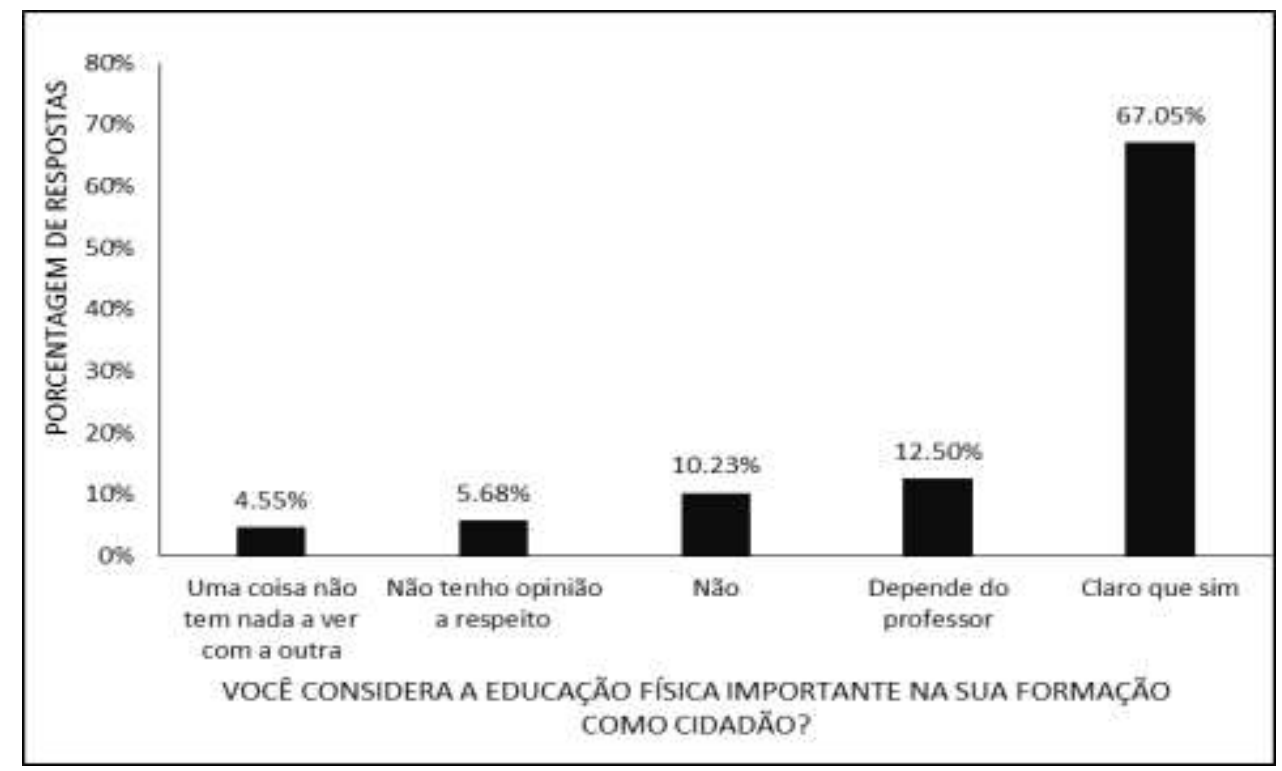

Fonte: Autores.

Como componente curricular a educação física tem sua importância e está além da prática de atividades físicas, sendo incumbida de formar um cidadão em sua plenitude. Partindo de um planejamento pedagógico, proporciona ao desenvolvimento a identidade de cada um dentro de uma visão de sociedade, mas respeitando os diferentes tipos de pensamento (Araujo \& Sousa, 2019).

O professor tem um papel fundamental nesse processo de formação durante o ensino médio. Mais uma vez os alunos apostam que depende do professor. Assim, ao criar suas aulas, o professor tem que ter me mente qual será sua contribuição para a formação dos educandos. Pensar em qual o modelo de pessoas que se deseja que atue em sociedade (Gutierrez, 2008).

Quanto a formação do cidadão, a educação física por meio da cultura corporal produz, qualifica e transforma as práticas corporais, possibilitando que desenvolva os direitos e deveres como qualquer cidadão (Araujo \& Sousa, 2019)

Quando perguntados sobre as aulas com atividade em grupo (Figura 13) seria tipo de aula que contribui para a formação do cidadão. Dos alunos, 2.27\% “Discorda muito", em seguida 3.41\% “Discorda”, já 7.95\% “Está em dúvida”, apresentando um aumento com 34.09\% “Concorda muito", e com 52.27\%" Concordam”. 
Figura 13 - Porcentagem de repostas do tipo de aula que contribui para a formação do cidadão e da cidadania: aulas com atividades em grupos.

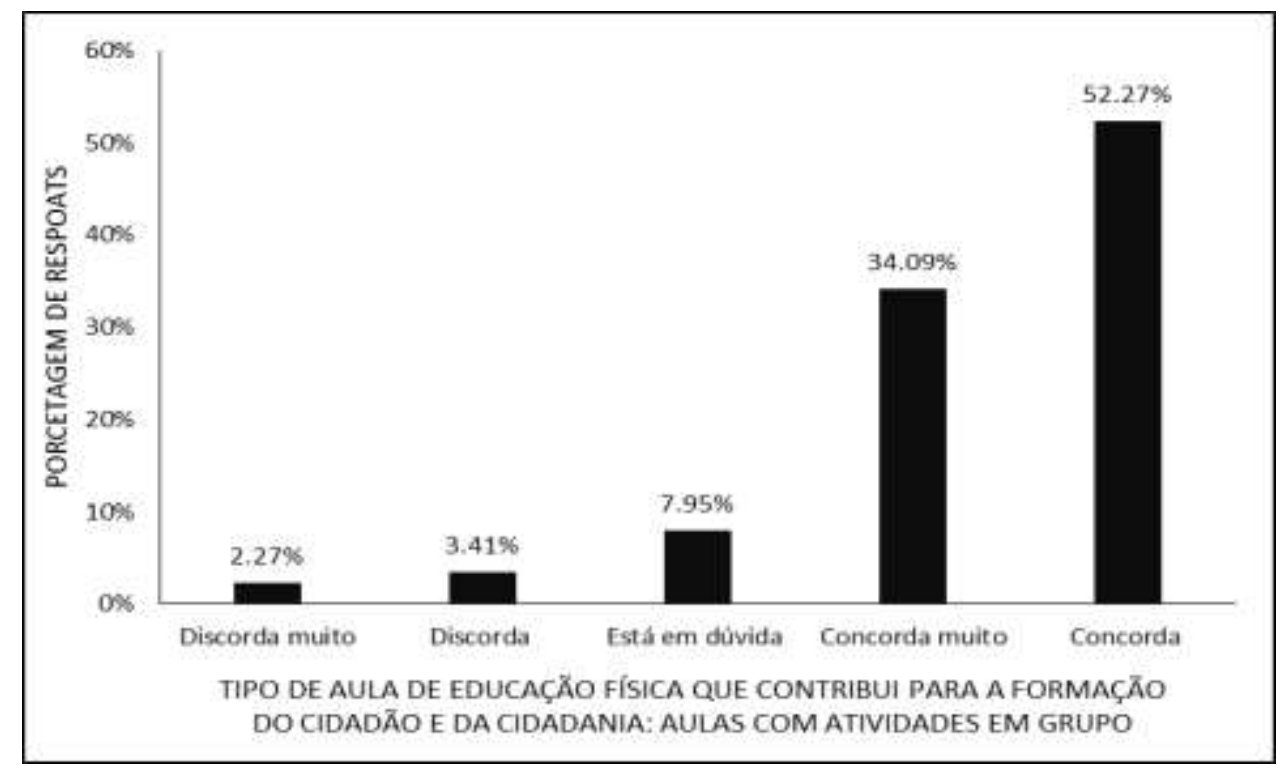

Fonte: Autores.

Neste resultado os educados mostram que acham importantes trabalhar em grupo, estar em contanto com o outro, fortalecendo ou criando vínculos. O ser humano na sua essência é um ser sociável, precisa de contanto para aprender a ser um agente da sociedade, ou seja, ser um cidadão, um homem real, material e completo (Silva \& Feldhaus, 2018). Sem uma relação com o outro, o homem não tem como educar-se, não satisfaz suas necessidades, não realiza suas metas, o sentindo da vida acontece na relação com o outro (Rampazzo, 2018).

Nas aulas de educação física, para proporcionar atividades em grupo, tem-se que ter uma organização do espaço escolar. As atividades, além da formação do intelectual, têm relação com a formação do aluno dentro dos princípios éticos, participativos. O espaço selecionado para ocorrer a aula torna-se um espaço vivo onde permite que a cidadania possa ser colocada em pratica em todo o momento (Thomaz \& Oliveira, 2009).

A cidadania não é um aspecto que vem de fora para dentro, começa em como a pessoa se relaciona com ela mesma, partindo dessa pratica expande para outras pessoas ao seu redor e a sociedade. Para isso o aluno precisa ser educado, estimulado, podendo essa educação ocorrer até mesmo antes do período escolar (Thomaz \& Oliveira, 2009).

As práticas corporais são as ferramentas para sujeito ativo fisicamente. Ser ativo ultrapassa a dimensão biológica, passando atingir a dimensão social, fazendo parte desse processo valores, atitudes que vão de encontro a falta de empatia, de ânimo. A cidadania ativa por meio da educação física proporciona uma liderança, entendimento em que o cidadão está consciente sobre o que acontece em sai vida, tem a habilidade e coragem para agir de forma apropriada, tanto de forma individual quanto em grupo. O ser ativo está em reação a cultural e a criticidade, é ter autonomia e inciativa para se envolver com os outros para trabalhar em uma mudança ou manter uma pratica social desejável (Onofre, 2017).

Ainda sobre a formação do cidadão, quando perguntados sobre a contribuição das aulas teóricas e práticas em que se discute sobre as atividades físicas e sua contribuição para a vida do cidadão Como mostra a Figura 14, tem uma pequena percentagem com 1.14\% "Discorda muito", logo em seguida com 3.41\% “Discorda”, já 14.77\% “Está em dúvida”, apresentando um aumento dos números com $37.50 \%$ “concordam muito" e $43.18 \%$ "Concordam” 
Figura 14 - Mostra a porcentagem de repostas sobre o tipo de aula de Educação Física que contribui para a formação do cidadão e da cidadania.

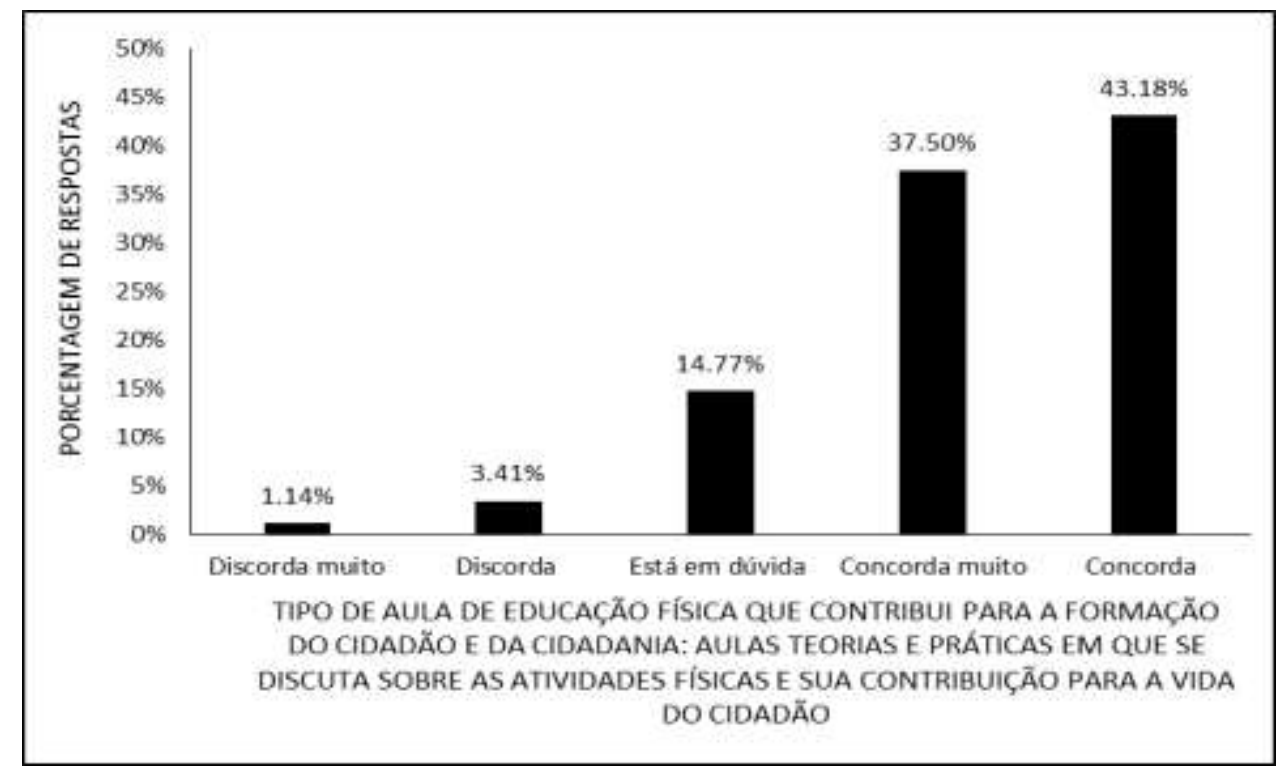

Fonte: Autores.

Os alunos percebem a união entre teoria e pratica como fundamental para a formação. Dentro do pressuposto de formação omnilateral da EPT, a união da teoria e a pratica é necessária para resultar em uma práxis, ou seja, como cidadão que vive em sociedade e atua na forma de modificá-la. Na práxis educativa coloca os saberes em movimento, construindo, reconstruindo, ensinando, aprendendo com a escola, livros, com as pessoas, com a história de cada um que compõe a realidade escolar ou social (Oliveira et al., 2013).

O professor de educação física, ao ter como função a formação de alunos mais críticos que aplique os conhecimentos fora da escola, terá que fazer o uso da práxis. A teoria e a pratica devem ser entendidas com o mesmo nível de importância, com reciprocidade. Afinal, as dimensões dos conteúdos não ocorrem de forma separadas (Santos \& Silva, 2012).

Unir a teoria e prática por meio da cultura corporal do movimento proporciona exercício da cidadania. Como componente curricular não se trata apenas de atividade física, uma vez que o professor pode utilizar diversos meios para as trabalhar. Em aula aborda-se a teoria tendo relação a fatos, curiosidades, informações, princípios que o aluno pode aplicar ou correlacionar coma realidade (Santos \& Silva, 2012)

Ao olhar para a realidade, percebe-se que está cheia de valores. Com bases nesses valores presentes na sociedade os alunos responderam quais os que poderiam ser ensinados durante as aulas. Como resultando, na Figura 15, têm-se 10.23\% "Morais", seguido de 32.95\% "Sociais" e 56.82\% "Físicos". 
Figura 15 - Porcentagem de repostas sobre os valores que poderiam ser ensinados nas aulas de educação física.

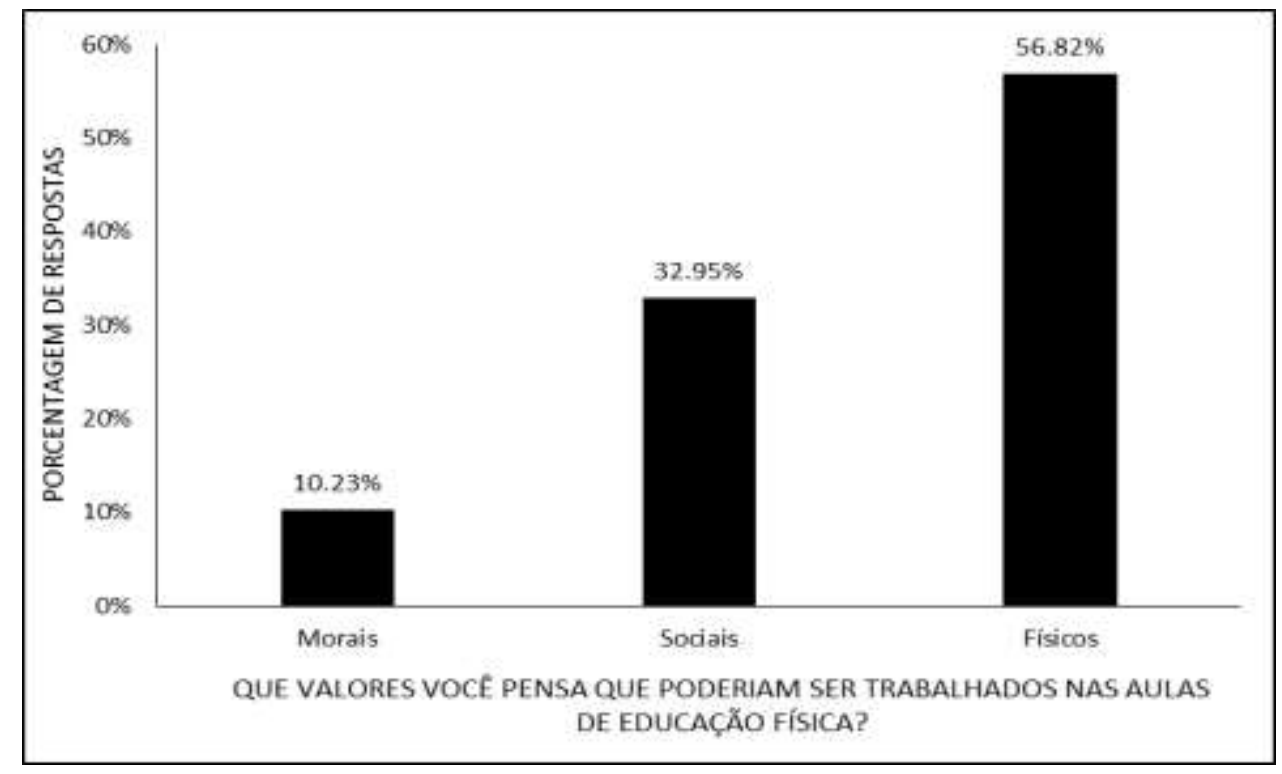

Fonte: Autores.

Sobre os valores existente na sociedade, Bickel et al. (2012) diz que os sujeitos são influenciados por diversos meios: internet, televisão, amigos, religião, família, livros entre outras formas que vão influenciar na construção do caráter. O mesmo acontece nas práticas corporais, como exemplo, lutas, esportes, danças etc. Nas aulas de educação física o professor tem que ficar atento para fazer um trabalho pedagógico que o aluno faça uma análise crítica sobre as atitudes que são reveladas durante a pratica de uma determinada atividade.

Para trabalhar os valores sinalizados pelos alunos a educação física deve ser inserida dentro de um contexto social. Ao tematizar as práticas, a educação física recebe um papel de transformador, superando uma educação física tradicional. Utilizandose das teorias críticas debate e trabalha os mais diversos tipos de valores. As aulas tornam-se um momento de reflexões e vivência de valores e atitudes (Acedo, 2009; Sá, 2019).

Visando a construção de valores, ao trabalhar com contexto se realiza uma pratica reflexiva sobre os valores da sociedade, esses que são de são expostos de forma direta ou indireta. Um trabalho para a construção e positivo, não reforçando certas atitudes que ferem valores morais, a ética e a estética (Furtado \& Morais, 2010).

Quando perguntado aos alunos se a educação física era a menos importante em comparação as outras, de acordo com a Figura 16, 3,41\% “Concordam muito”, em sequência 15,91\% "Está em dúvida”, já 17,05\% “Concordam”, e 20,45\% Discordam muito, junto com 43,18\% "Discordam". 
Figura 16 - Porcentagem de repostas sobre a comparação com as outras disciplinas a educação física se torna a menos importante para a formação global.

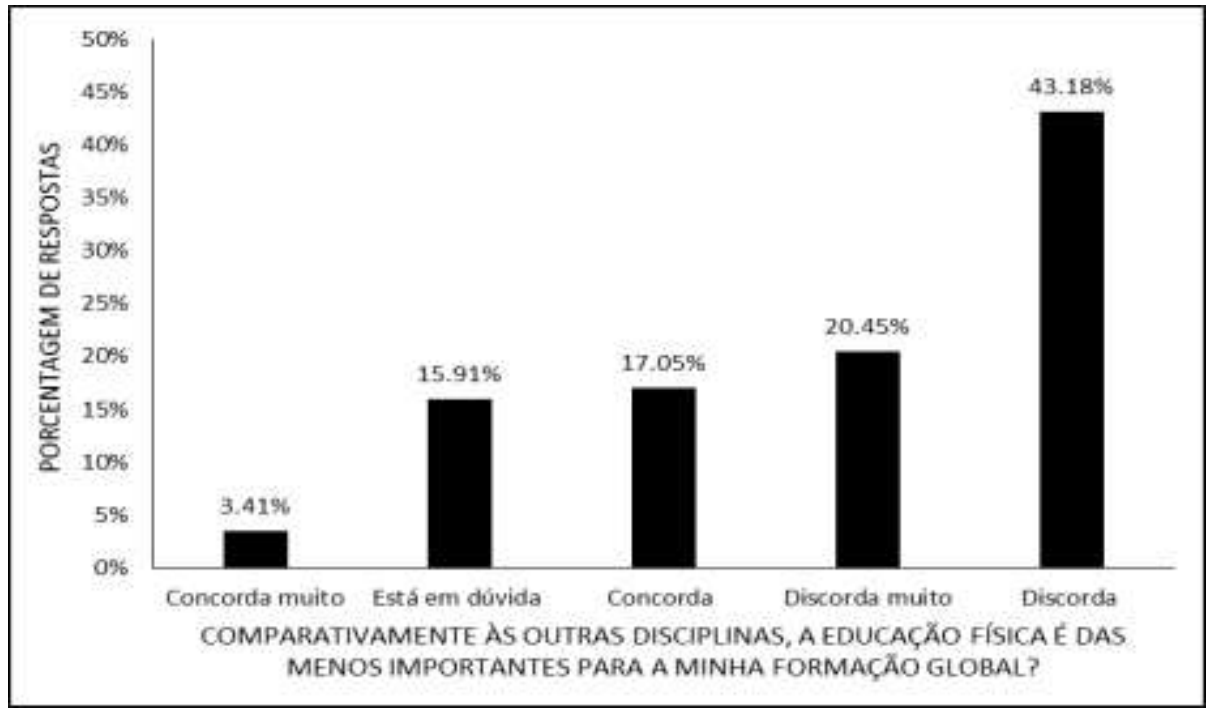

Fonte: Autores.

Os alunos discordam que a educação física seja uma das disciplinas menos importantes para a formação global. Segundo Boeira et al. (2017) para uma educação global, a educação física deve fazer parte do conteúdo escolar, a cultura corporal do movimento é um patrimônio criado pela humanidade que está presente no cotidiano de cada um.

Uma educação física para a formação total não está em praticar uma atividade sem entender, e sim que o aluno olhe para os objetos da educação física e possa escolher, vivenciar, planejar, transformar, faça um juízo dos valores que estão inseridos nas práticas corporais (Silva, 2010).

Sobre a educação global, uma de suas características é o trabalho do pensamento crítico. De acordo com a Figura 17, sobre o trabalhar o pensamento crítico no ensino médio, mostra que 2,27\% diz "Sempre”, logo em seguida com 19,32\% "Nunca", ainda os alunos com 19,32\% responderam "Raramente", já 25,00\% “Muitas vezes" e 34,09\% Às "vezes".

Figura 17 - Porcentagem de repostas sobre as competências gerais do Ensino Médio que foram trabalhadas: Pensamento crítico.

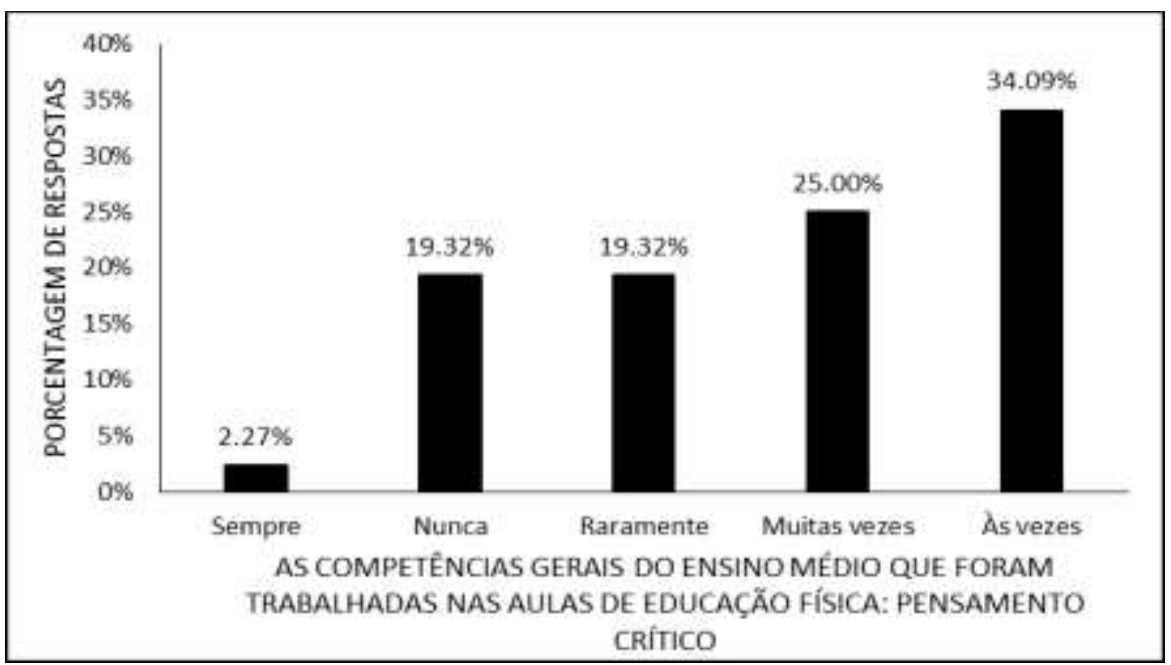

Fonte: Autores. 
Todo o processo de ensino-aprendizagem da educação física com uma caraterística omnilateral tem que estar dentro de uma temática. Partindo da análise crítica de uma situação-problema, busca-se trabalhar o pensamento crítico, do abstrato ao concreto dos fatos. O aprender está ligado ao conhecimento da realidade concreta, ou seja, da realidade que o aluno vivência, e só tem sentindo quando há uma aproximação critica dessa vivência. O conhecimento que o educando coloca em pratica é o resultado de um processo de compressão, reflexão e crítica do concreto (Libâneo, 1990; Pereira \& Alich 2015).

Monteiro (2017) afirma que a educação física escolar lida produzindo corpos, e partido disso, é necessário que tenha uma reflexão e crítica sobre os significados e construção desses corpos, como exemplo: gênero e o poder. Como intervenção para a construção da criticidade, a educação física lida com diversos temas como: saúde, qualidade de vida, mídia (Montiel et al., 2019).

Os dados mostram uma grande variedade sobre o ensino do pensamento crítico nas aulas. Essa variação é resultado da atuação do professor. De certa forma o docente pode apresentar uma dificuldade em trabalhar com o pensamento crítico pois é falha ou carência o que já acorre na formação inicial da faculdade/universidade. Ainda de acordo com os autores citados, a inexistência ou dificuldade em práticas de ensino orientadas para a construção da criticidade ocorre pelo perfil dos alunos, daqueles que abandonam a escola por causa do trabalho ou pela falta de sucesso no ensino regular (Lopes et al., 2015).

Outro aspecto da formação global, é o trabalho de valores e atitudes como espírito de solidariedade, cooperação e combate às injustiças. De acordo com 5,68\% diz "Nunca", em seguida com 5,68\% "Raramente", já 20,45\% "Sempre", e com 26,14\% “Às vezes” e 42,05\% “Muitas vezes” se nas aulas de educação física esses valores e atitudes foram trabalhadas.

Figura 18 - Porcentagem de repostas sobre as competências gerais do Ensino Médio que foram trabalhadas: Espírito de solidariedade, cooperação e combate às injustiças:

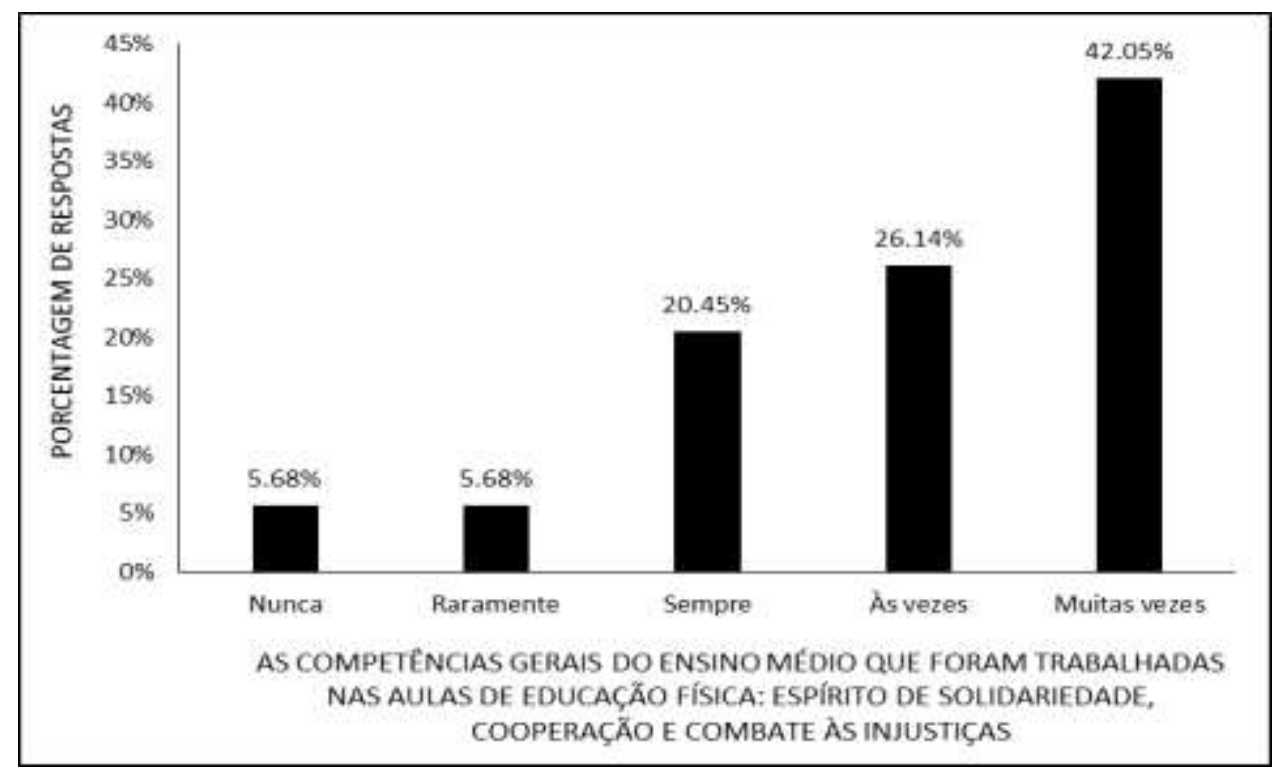

Fonte: Autores.

A formação do aluno dentro da EPT tem que estar em relação com as mais diversas dimensões da realidade. Tinôco (2007) relata que um ensino fragmentado acaba tornando-se menos solidário, apático. Cada vez que novas responsabilidades sociais aparecem a educação deve ser destinada a uma sensibilidade solidária.

Fica visível que o professor trabalha em nas suas aulas a solidariedade, cooperação e senso de justiça como mostram os resultados. Trabalhando essas características supera-se a ideia de corpo-mente, desenvolvendo a sensibilidade das emoções proporciona uma corporeidade cultuada e cultivada (Tinôco, 2007). 
Dessa forma, a educação física lida com conteúdo atitudinais. Com a solidariedade sendo um compromisso intencional, a ética estará presente. Ao trabalhar com temas como a ética cria-se um ambiente favorável de dissolução de qualquer tipo de preconceito. Prioriza-se o convívio escolar, levanta-se questões sobre o respeito ao próximo, o uso do diálogo, a justiça, a solidariedade, que são usados de forma autônoma pelos alunos (Furtado \& Morais, 2010).

As práticas corporais são muito mais que o simples deslocamento em uma quadra, praça ou sala de aula. É o trabalho de produção, reconhecimento de cultura em seu sentindo mais amplo. É mostrar para o aluno que competem e ao mesmo tempo aprendam a jogar com o outro, e não contra o outro. Essa lição incorpora valores e atitudes: solidariedade, cooperação e a luta contra injustiças que vão contra qualquer ideia de cada um por sim e Deus por todos (Carbonera \& Carbonera, 2008).

\section{Considerações Finais}

A educação física escolar ainda passa por um processo de valorização e importância, isso só é possível através de estudos e pesquisas sobre as diversas possibilidades dentro da área. Quando a educação física está dentro da escola, ela passa aderir os códigos e finalidades educativas. Dentro da educação profissional e tecnológica, o docente de educação física tem como objetivo a formação do cidadão omnilateral.

Para a formação omnilateral, a educação física tem bastante a contribuir. Como mostrado no decorrer da pesquisa os alunos não são apenas corpos restritos a dimensão biológica, são sujeitos históricos, sociáveis, com a sua cultura e filosofia. Essas características devem ser consideradas e trabalhadas pelo professor, assim ampliando o campo de discussão e conhecimento científico nas aulas de educação física.

Através dessa pesquisa evidenciou-se que os alunos reconhecem a importância do professor como um agente fundamental no processo de formação. Que muitas práticas e objetivos só serão realidade dependendo do docente. Então, o professor de educação física da EPT tem que ter em mente que o tipo de cidadão ele está ajudando a formar.

Ainda na percepção dos alunos do Instituto federal do Amapá uma aula de educação física tem que levar a técnica em consideração, mas não levar isso como prioridade. Para os educandos uma aula de educação física que possa ser uma ferramenta de transformação social torna-se uma aula mais desejável. Acrescentando ainda que para os educandos uma aula de educação física tem que ser lúdica, prezar pela cooperação e aproveitar o conhecimento que o aluno traz de sua vivencia.

E principalmente, os educandos percebem que a educação física é importante para uma formação humana omnilateral. Dentro do contexto do ensino médio técnico, em comparação com outras disciplinas a educação física não perde sua relevância. Que a educação física tendo o corpo e as práticas corporais como objeto de ensino em suas amplas dimensões possibilita uma educação mais reflexiva, critica, empática, dentro dos demais valores e atitudes que estão presentes na sociedade.

Os resultados apresentados pela pesquisa evidenciaram que os professores trabalham uma educação física que vai além do esporte pelo esporte, proporcionam aos alunos uma vivência de uma pratica mais crítica, que visa realmente contribuir para a formação do cidadão. As diversas maneiras de trabalhar os conteúdos junto com a experiência pratica de certa forma vão refletir em como os alunos percebem uma determinada componente curricular. E os educandos percebem que não há uma formação integral sem a presença da educação física, pois é uma área que lida com o ser humano como um todo, desde sua estrutura anatômica a desenvolvimento de nexos sociais.

Reconhece-se os limites presentes no estudo por causa do período pandêmico, não acontecendo um contato mais próximo com os educandos. Espera-se que essa pesquisa possa contribuir para novos estudos na área da educação física, que estimule um olhar e a curiosidade nessa área do conhecimento que é tão rica e ampla. Esse trabalho torna-se mais uma peça no quebra cabeça do conhecimento científico sobre a relação da educação física e a formação omnilateral. 


\section{Referências}

Acedo, L. M. (2009). Valores e atitudes na prática pedagógica do professor de Educação Física Universidade Estadual Paulista]. Rio Claro SP.

Almeida, L. d., \& Martins, F. D. (2020). Educação física escolar no ensino médio integrado: Limites e possibilidades de uma proposta de intervenção. Revista Prática Docente, 5(1), 100-120.

Alves, N. C., Wangenheim, C. G. V., Martins-Pacheco, L. H., \& Borgatto, S. F. (2021). Existem Concordância e Confiabilidade na Avaliação da Criatividade de Resultados Tangíveis da Aprendizagem de Computação na Educação Básica? . EduComp, 27-30.

Araujo, A. V., \& Sousa, F. J. F. (2019). Importância da educação física escolar na formação do indivíduo Centro Universitário UNIFACVEST].

Athayde, R. (2016). Jogos Digitais na Educação Física Escolar: Just Dance Now vai para sala de aula Universidade Federal de Santa Catarina (UFSC)]. Florianópolis SC.

Baczinski, A. V. d. D., \& Comar, S. R. (2019). A educação brasileira: Perspectivas para a formação omnilateral em tempos de capitalismo. Colloquium Humanarum, 16(2), 79-92.

Balbino, S. I., \& Urt, S. d. C. (2018). Prática Pedagógica em Educação Física para a Educação Integral em Tempo Integral. Pensar a Prática, 21 (4), 775-785.

Batista, A. P. (2014). Conhecimentos sobre o corpo: uma possibilidade de intervenção pedagógica nas aulas de educação física no ensino médio. IFRN.

Beggiato, C. L. (2009). A importância da educação física na percepção de uma comunidade escolar Universidade São Judas Tadeu - USJT].

Bickel, É. A., Marques, M. G., \& Santos, G. A. (2012). Esporte e sociedade: a construção de valores na prática esportiva em projetos sociais. EFDeportes.com, 17(171). https://www.efdeportes.com/efd171/esporte-e-sociedade-a-construcao-de-valores.htm

Boeira, W. N. d. S., Alessi, A., \& Fontana, E. C. (2017). A Visão Das Aulas De Educação Física: Relação Professor E Aluno $8^{\circ}$ Congresso Norte Paranaense de Educação Física Escolar - CONPEF, Londrina PR.

http://www.uel.br/eventos/conpef/portal/pages/arquivos/ANAIS\%20CONPEF\%202017/a\%20visao\%20das\%20aulas\%20129635-19945.pdf

Brait, L. F. R., Macedo, K. M. F. d., Silva, F. B. d., Silva, M. R., \& Souza, A. L. R. d. (2010). A relação professor/aluno no processo de ensino e aprendizagem. Itinerarius Reflectionis, 6(1). https://www.revistas.ufg.br/rir/article/view/40868

Brasil. (1997). Parâmetros Curriculares Nacionais: Educação Física. Brasília DF: MEC/SEF

Brasil. (2013). Resolução $n^{\circ}$ 466, de 12 de dezembro de 2012. Brasília DF: Diário Oficial da República Federativa do Brasil Acesso from http://bit.ly/1mTMIS3

Carbonera, D., \& Carbonera, S. A. (2008). A importância da dança no contexto escolar Faculdade Iguaçu - ESA]. Cascavel PR http://www.educadores.diaadia.pr.gov.br/arquivos/File/2010/artigos_teses/EDUCACAO_FISICA/monografia/DANCA_ESCOLA.pdf

Cardoso, C. A. Q., \& De Oliveira, N. C. M. (2019). A História Da Educação Integral/Em Tempo Integral Na Escola Pública Brasileira. InterMeio: Revista do Programa de Pós-Graduação em Educação-UFMS, 25(50), 57-77.

Cardoso, L. C. R., Araújo, G. C. d. S., Souza, M. F. d., Ferreira, P. S. G., Gonçalves, S. d. S., \& Santos, V. B. d. (2011). A importância do planejamento para o professor de Educação Física. EFDeportes.com, 16(157). https://www.efdeportes.com/efd157/a-importancia-do-planejamento-para-educacao-fisica.htm

Cavalheiro, J. K., \& Gomes, D. (2014). História Da Educação Física No Brasil Anais da XIX Semana de Iniciação Científica, Guarapuava PR.

Chaer, G., Diniz, R. R. P., \& RIbeiro, E. A. (2011). A técnica do questionário na pesquisa educacional. Revista Evidência, 7(7), $251-266$.

Chaves, A. P., \& Goergen, P. L. (2017). Ética e estética na formação humana. Revista Exitus, 7(2), 331-349.

Coêlho, I. M., \& Guimarães, G. (2012). Educação, escola e formação. Inter-Ação, 37(2), 1-17.

Costa, M. R. J. (2009). Educação Física para humanização da educação profissional e tecnológica: um estudo no RS Universidade de Santa Cruz do Sul UNISC]. Santa Cruz do Sul RS.

Cruz, A. J., Almeida, A. M., Franco, D. B., Silva-Speakes, K. M., Montero, M. F. A. G., Silva-Speakes, N. F., Sanches, S. M., Souza, S. B., \& Silva, W., R,. (2018). O Caminho das Pedras: Percursos Metodológicos de Pesquisa em Educação. Paco Editorial.

Dal-Farra, R. A., \& Lopes, P. T. C. (2013). Métodos mistos de pesquisa em educação: pressupostos teóricos. Nuances: estudos sobre Educação, 24(3), 67-80.

Daolio, J. (2002). Jogos esportivos coletivos: dos princípios operacionais aos gestos técnicos - modelo pendular a partir das idéias de Claude Bayer. Rev. Bras. Ciên. e Mov., 10(4), 99-104.

Dos Santos, R., \& Freire, E. D. S. (2006). Educação física e esporte no terceiro setor: estratégias utilizadas no ensino e aprendizagem de valores, atitudes e normas no projeto esporte talento. Revista Mackenzie de Educação Física e Esporte, 5(1), 35-45.

Duarte, E. C. M., \& Jacomeli, M. R. M. (2017). A Educação Integral Na Perspectiva Histórico-Crítica: Para Além Da Ampliação Do Tempo Escolar. Educação: Teoria e Prática, 27(56), 562-574.

Duarte, Z. S. (2014). A especificidade da educação física na perspectiva de uma formação omnilateral V Seminário De Metodologia De Ensino Da Educação Física (SEMEF), São Paulo SP. 
Feitosa, J. L. A. (2008). Educação Física: até que ponto educa? Universidade Federal Rural do Rio De Janeiro]. Seropédica RJ.

Finck, S. C. M. (2011). A Educação Física e o esporte na escola: cotidiano, saberes e formação. Ibpex.

Freire, E. d. S., Verenguer, R. d. C. G., Soriano, J. B., Santos, E. A. D., \& Pinto, M. R. D. A. (2010). A dimensão atitudinal nas aulas de educação física: conteúdos selecionados pelos professores. Revista da Educação Física/UEM, 21(2), 223-235.

Freire, P. (1969). Pedagogia da autonomia: Saberes necessários à prática educativa. Paz e Terra.

Freire, P. (1996). Pedagogia da autonomia: Saberes necessários à prática educativa. Paz e Terra.

Freire, P. (2002). Pedagogia da autonomia: saberes necessários à prática educativa. Paz e Terra.

Furtado, D. S., \& Morais, P. J. d. S. d. (2010). Bullying nas aulas de Educação Física e o papel do professor. EFDeportes.com, 15(147). https://www.efdeportes.com/efd147/bullying-nas-aulas-de-educacao-fisica.htm

Furtado, R. S., Barreto, L. L. A., \& Ramos, A. H. F. (2019). Pedagogia crítico-superadora e o modelo pendular: uma aproximação necessária para o ensino dos esportes coletivos na escola. Cadernos UniFOA, 14(40), 83-94.

Gallardo, J. S. P., Campos, L. A. S., \& Gutierrez, L. A. L. (2003). Panorama da Preparação e Atuação Profissional em Educação Física Escolar Brasileira. In J. S. P. Gallardo (Ed.), Educação Física Escolar: do berçário ao ensino médio (pp. 11-24). Editora Lucerna. https://www.unirios.edu.br/internas/biblioteca/servicos/arquivos/ebooks/educacao_fisica_escolar_do_bercario_ao_ensino_medio.pdf

Garcia, A. d. C., Dorsa, A. C., Oliveira, E. M. d., \& Castilho, M. A. d. (2018). Educação Profissional no Brasil: origem e trajetória. Revista Vozes dos Vales, 12, $1-18$.

Gasparin, J. L., \& Petenucci, M. C. (2014). Pedagogia histórico crítica: da teoria à prática no contexto escolar. Dia a dia Educação, 2, 2289-2288,

Guimarães, A. A., Pellini, F. d. C., Araujo, J. S. R. d., \& Mazzini, J. M. (2001). Educação física escolar: Atitudes e valores. Motriz, 7(1), 17-22.

Gutierrez, L. A. L. (2008). Formação humana e ginastica geral na educação fisicica Universidade Estadual de Campinas,]. Campinas SP.

Haddad, C. R., \& Pereira, M. F. R. (2013). Pedagogia histórico-crítica e psicologia histórico cultural: Inferências para a formação e o trabalho de professores. Germinal: Marxismo e Educação em Debate, 5(2), 106-117.

Junior, R. C. H. (2013). A importância das atividades lúdicas nas aulas de Educação Física no Ensino Médio. GovPR. Acesso em 28 Junho 2021 from http://www.diaadiaeducacao.pr.gov.br/portals/cadernospde/pdebusca/producoes_pde/2013/2013_unicentro_edfis_artigo_ricardo_carlos_hirt_junior.pdf Júnior, W. M., Almeida, B. S., \& Souza, J. (2019). Introdução à sociologia do esporte. InterSaberes.

Ladwig, M. A., Vazou, S., \& Ekkekakis, P. (2018). "My Best Memory Is When I Was Done with It": PE Memories Are Associated with Adult Sedentary Behavior. Translational Journal of the ACSM, 3(16), 119-129

Landis, J. R., \& Koch, G. G. (1977). The Measurement of Observer Agreement for Categorical Data. Biometrics, 33(1), $159-174$.

Libâneo, J. C. (1990). Democratização da Escola Pública. Loyola.

Lima, L. C. M. D. (2018). Propriedades Psicométricas Da Versão Brasileira Do Questionário Rapid Estimate Of Adult Literacy In Dentistry (Breald-30) Aplicado Em Adolescentes Universidade Estadual da Paraíba]. Campina Grande PB.

Lizzi, M. S. S. S., \& Favoreto, A. (2018). Concepção De Educação Integral: fundamentos e (res) significações na política educacional para o Ensino Médio. Cadernos de Pesquisa, 25(2), 129-146.

Lopes, S., Vieira, R. M., \& Moreira, A. (2015). Formação de professores no uso de ferramentas da web 2.0 com infusão do pensamento crítico: Estudo de caso. In C. Dominguez (Ed.), Pensamento crítico na educação: desafios atuais (pp. 311 p.). UTAD. https://www.pensamiento-critico.com/archivos/ebookutad.pdf

Marcolino, F. S., \& Lima, P. R. F. (2019). A importância da Educação Física no ensino médio integrado: concepção docente no IFCE Campus Canindé. Research, Society and Development, 8(12), e068121392.

Marin, A. C., Junger, A. P., Assayag, R. M., \& Amaral, L. H. (2019). A Educação Profissional No Brasil: Breve Histórico Do Artifície Nas Casas Da Moeda Ao Profissional Tecnólogo Amparado Pela LDB De 1996. Humanidades \& Inovação, 6(2), 79-93.

Martinelli, C. R., Merida, M., Rodrigues, G. M., Grillo, D. E., \& Souza, J. X. d. (2006). Educação física no ensino médio: motivos que levam as alunas a não gostarem de participar das aulas. Revista Mackenzie de Educação Física e Esporte, 5(2), 13-19.

Marx, K. (2004). Manuscritos econômico-filosóficos. Boitempo.

Marx, K., \& Engels, F. (2011). Textos sobre Educação e Ensino. Navegando. https://www.marxists.org/portugues/marx/ano/mes/ensino.pdf

Minuzzi, E. D., Baccin, B. A., \& Coutinho, R. X. (2019). Prática profissional integrada (PPI) - dos princípios à ação no Ensino Médio Integrado. Educitec Revista de Estudos e Pesquisas sobre Ensino Tecnológico, 5(12), 250-273.

Monteiro, M. V. P. (2017). A construção identitária nas aulas de educação física. Revista Brasileira de Educação Física e Esporte, $22,339-359$.

Montiel, F. C., Afonso, M. d. R., Santos, L. L. d., \& Silva, P. d. R. L. d. (2019). Ética, autonomia e pensamento crítico nas aulas de Educação Física no ensino médio. Motrivivência, 31(58), 1-21.

Mota, J. (2019). Utilização do Google Forms na pesquisa acadêmica. Humanidades \& Inovação, 6(12), 371-373. 
Neu, M., Tornquist, L., Burgos, M. S., Weiss, G. F., \& Tornquist, D. (2012). Valores nas aulas de Educação Física e no esporte escolar. EFDeportes.com, 17(169). Nolasco, R. C. (2007). As percepções pessoais, crenças e valores dos alunos na disciplina de educação física Universidade Castelo Branco]. Rio de Janerio RJ.

Oliveira, F. F. B. d., Bôto, A. H. V., Silva, S. C. d., \& Cavalcante, M. M. D. (2013). A relação entre teoria e prática na formação inicial docente: percepções dos licenciandos de pedagogia V Fórum Internacional de Pedagogia, Vitória da Conquista BA. https://www.editorarealize.com.br/editora/anais/fiped/2013/Trabal ho_Comunicacao_oral_idinscrito_45_817429beae1565e20c320420a758723d.pdf

Oneto, A. F. O. N. (2013). Atitudes dos alunos face à disciplina de Educação Física: influência das variáveis ano de escolaridade, contexto de ensino e nível socioeconómico Universidade do Minho]. Portugal PT.

Onofre, M. (2017). A qualidade da educação física como essência da promoção de uma cidadania ativa e saudável. Retos: nuevas tendencias en educación fisica, deporte y recreación $(31), 328-333$.

Paranhos, R., Filho, D. B. F., Rocha, E. C. d., Júnior, J. A. d. S., \& Freitas, D. (2016). Uma introdução aos métodos mistos. Sociologias, $18(42)$, 384-411.

Pereira , S., \& Alich, V. A. (2015). A avaliação do pensamento crítico numa perspetiva psicológica. In C. Dominguez (Ed.), Pensamento crítico na educação: desafios atuais (pp. 311 p.). UTAD. https://www.pensamiento-critico.com/archivos/ebookutad.pdf

Ramos, M. N. (2014). História e política da educação profissional Instituto Federal do Paraná.

Rampazzo, L. (2018). Antropologia: Religiões e valores cristãos. Paulus.

Ribeiro, G. D. M., Silva, J. W. D., \& Kogut, M. C. (2015). Contribuições do professor de educação física na formação cidadã do aluno no ensino médio XIX Congresso Brasileiro de Ciências do Esporte / VI Congresso Internacional de Ciências do Esporte, Vitório ES. http://congressos.cbce.org.br/index.php/conbrace2015/6conice

Rigoni, A. C. C. (2010). Educação do corpo e religião: questões à educação física escolar. In J. Daolio (Ed.), Educação Física Escolar: olhares a partir da cultura (pp. 137-151). Autores Associados.

Sá, K. R. (2019). Currículo do ensino médio integrado do IFMG: a partitura, a polifonia e os solos da educação fisica Universidade de São Paulo]. São Paulo SP.

Santos, D. P. (2018). Cap. 2 - O cultivo do conhecimento ético, a formação de professores e sua praxis na educação profissional e tecnológica (EPT). In K. R. Mota, L. L. S. Pereira , \& M. C. T. Heberlein (Eds.), A Formação Docente e a Educação Profissional e Tecnológica: Pesquisas em Foco (pp. 228p.). Paco Editorial.

Santos, L. d. S., \& Santos, L. d. S. (2020). A educação em marx: Algumas considerações acerca da formação omnilateral. In D. G. O. d. Silva, L. H. d. Brito, \& M. A. B. d. Novaes (Eds.), A crítica da educação na sociedade do capital (pp. 62-74). EdUECE.

Santos, O. J. G., \& Silva, M. C. (2012). Teoria e prática: as implicações nas aulas de Educação Física escolar. EFDeportes.com, 17(170). https://www.efdeportes.com/efd170/teoria-e-pratica-nas-aulas-de-educacao-fisica.htm

Saraiva, A. C. A., Fenker, N. S., Chaves, E. d. S., Leão, M. M., Santos, M., Caldeira, L., \& Paim, M. C. C. (2017). O esporte na formação integral do cidadão Anais do XXII Seminário Internacional de Educação, Cachoeira do Sul. https://www.ulbracds.com.br/index.php/sieduca/issue/view/12/showToc

Severino, A. J. (2006). A busca do sentido da formação humana: tarefa da Filosofia da Educação. Educ. Pesqui., 32(3), 619-634.

Silva, J. L. S., \& Feldhaus, C. (2018). O conceito de essência humana a partir da concepção antropológica de Ludwig Feuerbach. Revista Dialectus(12), 284302. http://www.periodicos.ufc.br/dialectus/article/view/33212/73271

Silva, M. A. d., Silva, L. O., \& Molina Neto, V. (2015). Possibilidades da educação física no ensino médio técnico. Movimento (ESEFID/UFRGS), 22(1), 325336.

Silva, M. G. (2010). A importância da Educação Física como componente curricular da educação básica na formação do cidadão do ensino fundamental: estudo de caso com alunos do $9^{\circ}$ ano da rede pública estadual da cidade de Resende, RJ. EFDeportes.com, 17(171). https://www.efdeportes.com/efd171/a-importanciada-educacao-fisica-na-formacao.htm

Silva, S. C. d. (2011). O Processo ensino-aprendizagem nas aulas de educação física no curso técnico de agropecuária do IFMT/ Campus Cáceres Universidade Federal Rural do Rio de Janeiro]. Seropédica RJ.

Silva, S. L. (2019). A Dimensão da afetividade na relação professor/aluno. Humanidades \& Inovação,, 6(2), $168-175$.

Sousa, A. R. S., \& Simeoni , M. C. (2014). Resgatando o conteúdo estruturante jogos e brincadeiras no ensino médio: Uma visão criativa e lúdica. In CadernosPDE (Ed.), Os desafiosda escola pública paranaense na perspectiva do professor PDE (pp. 2-11). GovPR. http://www.diaadiaeducacao.pr.gov.br/portals/cadernospde/pdebusca/producoes_pde/2014/2014_uenp_edfis_pdp_ana_rosa_dos_santos.pdf

Souza, A. L. D. (2016). Educação em valores no contexto escolar: Um estudo de caso Universidade Federal do Espírito Santo].

Souza, E., \& Benites, L. C. (2021). A Educação Física no Ensino Médio integrado: Análise de teses e dissertações defendidas em programas brasileiros de pósgraduação. Research, Society and Development, 10(4), e11610413998.

Souza, F. C. S. (2014). Ensino médio integrado à educação profissional: expansão e desafio para os institutos federais. In F. C. S. Souza (Ed.), Livro 3: Didática e Prática de Ensino na relação com a Sociedade. UECE.

Tavares, M. E. P. A., Souza, M. J. A. d., Lima, M. X. d. M., \& Coutinho, D. J. G. (2019). Afetividade: fator indispensáel à aprendizagem. Brazilian Journal of 
Research, Society and Development, v. 10, n. 10, e22101018373, 2021

(CC BY 4.0) | ISSN 2525-3409 | DOI: http://dx.doi.org/10.33448/rsd-v10i10.18373

Development, 5(11), 25710-25717.

Thomaz, L., \& Oliveira, R. C. (2009). A educação e a formação do cidadão crítico, autônomo e participativo. Dia-a-dia Educação, 1-25.

Tinôco, E. J. B. (2007). Educar para a solidariedade: uma perspectiva para a educação física escolar Universidade Federal do Rio Grande do Norte]. Natal RN. https://repositorio.ufrn.br/bitstream/123456789/27102/1/EducarSolidariedade_Tinoco_2007.pdf

Viana, V. N., Fecury, A. A., \& Dias, C. A. G. M. (2020). Formação Humana Integral/Omnilateral. In V. N. Viana \& C. A. G. M. Dias (Eds.), Educação fỉsica e EPT (Vol. 1, pp. 15-23). Centro de Pesquisa. https://doi.org/10.32749/1/educacao/educacao-fisica-e-ept-2

Viana, V. N., Oliveira, E. d., \& Dias, C. A. G. M. (2020). O Papel Da Educação Física Na Ept - De Nilo Peçanha ao Instituto Federal. In V. N. Viana \& C. A. G.

M. Dias (Eds.), Educação fisica e EPT (Vol. 1, pp. 07-14). Centro de Pesquisa. https://doi.org/10.32749/1/educacao/educacao-fisica-e-ept-1 